\title{
Flow-induced protein kinase A-CREB pathway acts via BMP signaling to promote HSC emergence
}

\section{Citation}

Kim, P. G., H. Nakano, P. P. Das, M. J. Chen, R. G. Rowe, S. S. Chou, S. J. Ross, et al. 2015. "Flowinduced protein kinase A-CREB pathway acts via BMP signaling to promote HSC emergence." The Journal of Experimental Medicine 212 (5): 633-648. doi:10.1084/jem.20141514. http:// dx.doi.org/10.1084/jem.20141514.

\section{Published Version}

doi:10.1084/jem.20141514

\section{Permanent link}

http://nrs.harvard.edu/urn-3:HUL.InstRepos:23845297

\section{Terms of Use}

This article was downloaded from Harvard University's DASH repository, and is made available under the terms and conditions applicable to Other Posted Material, as set forth at http:// nrs.harvard.edu/urn-3:HUL.InstRepos:dash.current.terms-of-use\#LAA

\section{Share Your Story}

The Harvard community has made this article openly available.

Please share how this access benefits you. Submit a story.

\section{Accessibility}




\title{
Flow-induced protein kinase A-CREB pathway acts via BMP signaling to promote HSC emergence
}

\author{
Peter Geon Kim, ${ }^{1,2,3}$ Haruko Nakano, ${ }^{4}$ Partha P. Das, ${ }^{1}$ Michael J. Chen, ${ }^{1,2,3}$ \\ R. Grant Rowe, ${ }^{1,2,3}$ Stephanie S. Chou, ${ }^{1,2,3}$ Samantha J. Ross, ${ }^{1,2,3}$ \\ Kathleen M. Sakamoto, ${ }^{5}$ Leonard I. Zon, ${ }^{1,2,3}$ Thorsten M. Schlaeger, ${ }^{1,2,3}$ \\ Stuart H. Orkin, ${ }^{1}$ Atsushi Nakano, ${ }^{4}$ and George Q. Daley ${ }^{1,2,3}$
}

'Division of Pediatric Hematology/Oncology, Boston Children's Hospital and Dana Farber Cancer Institute; Howard Hughes Medical Institute, Harvard Stem Cell Institute; ${ }^{2}$ Stem Cell Transplantation Program, Division of Pediatric Hematology/ Oncology, Boston Children's Hospital and Dana Farber Cancer Institute; and ${ }^{3}$ Department of Biological Chemistry and Molecular Pharmacology, Harvard Medical School, Boston, MA 02115

${ }^{4}$ Department of Molecular Cell and Developmental Biology, Eli and Edythe Broad Center of Regenerative Medicine and Stem Cell Research, Jonsson Comprehensive Cancer Center, Molecular Biology Institute, University of California, Los Angeles, Los Angeles, CA 90095

5Division of Pediatric Hematology/Oncology, Lucile Packard Children's Hospital, Stanford University School of Medicine, Stanford, CA 94305

Fluid shear stress promotes the emergence of hematopoietic stem cells (HSCs) in the aortagonad-mesonephros (AGM) of the developing mouse embryo. We determined that the AGM is enriched for expression of targets of protein kinase $A$ (PKA)-cAMP response elementbinding protein (CREB), a pathway activated by fluid shear stress. By analyzing CREB genomic occupancy from chromatin-immunoprecipitation sequencing (ChIP-seq) data, we identified the bone morphogenetic protein (BMP) pathway as a potential regulator of CREB. By chemical modulation of the PKA-CREB and BMP pathways in isolated AGM VEcadherin $^{+}$cells from mid-gestation embryos, we demonstrate that PKA-CREB regulates hematopoietic engraftment and clonogenicity of hematopoietic progenitors, and is dependent on secreted BMP ligands through the type I BMP receptor. Finally, we observed blunting of this signaling axis using Ncx1-null embryos, which lack a heartbeat and intravascular flow. Collectively, we have identified a novel PKA-CREB-BMP signaling pathway downstream of shear stress that regulates HSC emergence in the AGM via the endothelial-tohematopoietic transition.

\section{CORRESPONDENCE}

George 0. Daley: george.daley@

childrens.harvard.edu

Abbreviations used: AGM, aorta-gonad-mesonephros; BMP, bone morphogenetic protein; ChIP-seq, chromatin immunoprecipitation sequencing; CREB, cAMP response element-binding protein; ESC, embryonic stem cell; HSC, hematopoietic stem cell; $\mathrm{mESC}$, mouse ESC; PKA, protein kinase A; PSp, paraaortic splanchnopleura.
Embryonic hematopoietic development in the mouse proceeds through defined stages. The first hematopoietic cells of the erythroid lineage develop in the extraembryonic yolk sac at embryonic day 7.5 (E7.5; Moore and Metcalf, 1970). At E9, hematopoietic stem cell (HSC) activity from the yolk sac and paraaortic splanchnopleura (PSp) can be detected when transplanted into neonatal mice (Yoder et al., 1997; Arora et al., 2014). HSCs that engraft lethally irradiated adult recipients emerge in the aortagonad-mesonephros (AGM) region at E10-11 (Medvinsky and Dzierzak, 1996; North et al., 2002). These HSCs later colonize additional organs required for adult hematopoiesis and possess the ability to reconstitute multiple hematopoietic lineages.
The development of the murine circulatory system at E8.5 coincides with the development of more definitive hematopoietic compartments, including HSCs and the lymphoid lineage. Accordingly, recent studies have linked biomechanical forces, such as blood flow-induced shear stress, to hematopoietic development (Adamo et al., 2009; North et al., 2009). In these studies, genetic mutants lacking intravascular circulation were used to demonstrate the reduction in hematopoietic emergence in the AGM and nitric oxide signaling was implicated in blood

Q 2015 Kim et al. This article is distributed under the terms of an AttributionNoncommercial-Share Alike-No Mirror Sites license for the first six months after the publication date (see http://www.rupress.org/terms). After six months it is available under a Creative Commons License (Attribution-NoncommercialShare Alike 3.0 Unported license, as described at http://creativecommons.org/ licenses/by-nc-sa/3.0/). 
flow-dependent AGM hematopoiesis (Adamo et al., 2009; North et al., 2009; Wang et al., 2011). Although chimeric analysis demonstrated a cell autonomous requirement for nitric oxide signaling in zebrafish (North et al., 2009), whether this pathway directly promotes hematopoiesis remains an open question due to the vasodilatory effect of nitric oxide donors and their effects on smooth muscle. Apart from these observations, signaling pathways responsible for flow-dependent hematopoietic induction have not been characterized.

Activation of protein kinase A (PKA) and its downstream target cAMP response element-binding protein (CREB) by exogenous shear stress has been observed in diverse cell types, including chondrocytes and osteocytes (Cherian et al., 2003; Ogawa et al., 2014). The classic mechanism of PKA activation involves the binding of a ligand to a $G$ proteincoupled receptor and activation of adenylyl cyclase, which converts ATP into the second messenger cyclic AMP (cAMP). The binding of cAMP to PKA releases catalytic subunits that phosphorylate CREB in the nucleus. In differentiating mouse embryonic stem cells (mESCs), PKA-CREB has been linked to endothelial and hematopoietic differentiation via binding of CREB to the Etv2 promoter, which up-regulates pro-hematopoietic factors such as Gata2 and Scl/Tal1 (Yamamizu et al., 2012). Moreover, the PKA-CREB signaling pathway has been explored in the context of the prostaglandin $\mathrm{E}_{2}$ signaling pathway in zebrafish, where it promotes AGM hematopoiesis via activation of the Wnt pathway (Goessling et al., 2009). However, whether this pathway is conserved in the mouse is unclear, especially given conflicting reports on Wnt signaling in AGM hematopoiesis (Ruiz-Herguido et al., 2012; Chanda et al., 2013). Prostaglandin $\mathrm{E}_{2}$ also directly activates several pathways including PI3K-AKT and ERK-MAPK, which makes it difficult to conclude that PKA-CREB is the sole mediator of the pro-hematopoietic effects of this molecule (Alfranca et al., 2006). Given the shear-responsiveness of the PKA-CREB pathway and its implication in early embryonic hematopoiesis in other species, we investigated the possible role of shear stress-activated PKA-CREB signaling during AGM hematopoiesis in the mouse.

We first verified that this pathway is activated by shear stress in VE-cadherin ${ }^{+}$endothelial cells and present in the murine AGM, specifically in the cells lining the dorsal aorta. We then conducted a bioinformatics-based screen using microarray data on CREB overexpression and CREB chromatin immunoprecipitation-sequencing (ChIP-Seq) data using data available at Encyclopedia of DNA Elements (ENCODE) and elsewhere to identify regulators of CREB function in hematopoietic cells (Esparza et al., 2008; Jolma et al., 2010; Pencovich et al., 2011; Raney et al., 2011; Trompouki et al., 2011; Martens et al., 2012). Using insight gained from bioinformatics, we discover that the bone morphogenetic protein (BMP) signaling pathway acts downstream of PKA-CREB signaling in regulating AGM hematopoiesis. Finally, we show that this is a blood flow-dependent pathway by demonstrating the abrogation of PKA-CREB-BMP signaling axis in
Ncx1-null embryos, which lack a heartbeat and intravascular flow. Our data thus document a blood-flow dependent pathway regulating hematopoietic development.

\section{RESULTS CREB activation in the AGM}

To assess the role of the CREB pathway in hematopoiesis, we examined CREB-mediated gene expression programs across various embryonic and adult hematopoietic tissues and found marked enrichment of CREB target genes in the aorta-gonad-mesonephros (AGM) relative to other tissues (Fig. 1 A; McKinney-Freeman et al., 2012). CREB mRNA expression was similar among hematopoietic tissues, suggesting a posttranscriptional mechanism of target gene activation (Fig. 1 B). Because phospho-CREB at S133 is required for its transcriptional activity (Gonzalez and Montminy, 1989), we examined the distribution of S133-phosphorylated CREB in the E11.5 AGM, a time point coinciding with HSC emergence from the endothelium (North et al., 2002; Chen et al., 2009; Bertrand et al., 2010; Boisset et al., 2010). Some cells lining the aortic endothelium were S133 phosphorylated (Fig. $1 \mathrm{C}$ ), which raises the possibility of a shear stress-mediated effect. We also examined phospho-CREB in E10.5 embryos and obtained similar results (Fig. 1 D). Interestingly, most cells that were positive for Sca1-GFP, which marks the emerging HSCs in the endothelium (de Bruijn et al., 2002; Chen et al., 2011), also coexpressed phospho-CREB (Fig. 1 E). Because other S133-phosphorylated regions also included the ventral mesenchyme, notochord and the neural tube (Fig. 1, C and D), we examined the relationship between phosphoCREB and shear stress more closely in isolated VE-cadherin ${ }^{+}$ cells from differentiated mESCs, which is a more accessible endothelial cell type. Shear stress increased S133 phosphorylation of CREB in a time-dependent manner (Fig. 1 F). The concomitant phosphorylation of $\beta$-catenin at $\mathrm{S} 675$, a unique site for protein kinase A (PKA) phosphorylation (Hino et al., 2005), indicated shear-induced PKA activity (Fig. 1 F). Therefore, PKA phosphorylation of CREB in the AGM is likely dependent on blood flow.

\section{Genomic binding and interaction of CREB in K562 cells}

We next took advantage of published microarray data on CREB overexpression in human leukemic K562 cells as a model of hematopoietic stem/progenitor cells to gain insight into the role of the PKA-CREB pathway (Esparza et al., 2008). To correlate gene transcription with transcription factor binding to the genome, we examined the active promoters of 447 genes that were up-regulated by CREB overexpression (p-value cut-off, 0.05) for CREB genomic occupancy by analyzing the K562 chromatin immunoprecipitation-sequencing (ChIP-seq) data (Fig. 2 A; Raney et al., 2011). We defined active promoters as having histone $\mathrm{H} 3 \mathrm{~K} 4$ trimethylation (H3K4me3) and H3K27 acetylation (H3K27ac) but lacking H3K27 trimethylation (H3K27me3; Barski et al., 2007; Koch et al., 2007). We screened for regulators of the CREB pathway by examining transcription factor co-occupancy (Fig. 2 B). 

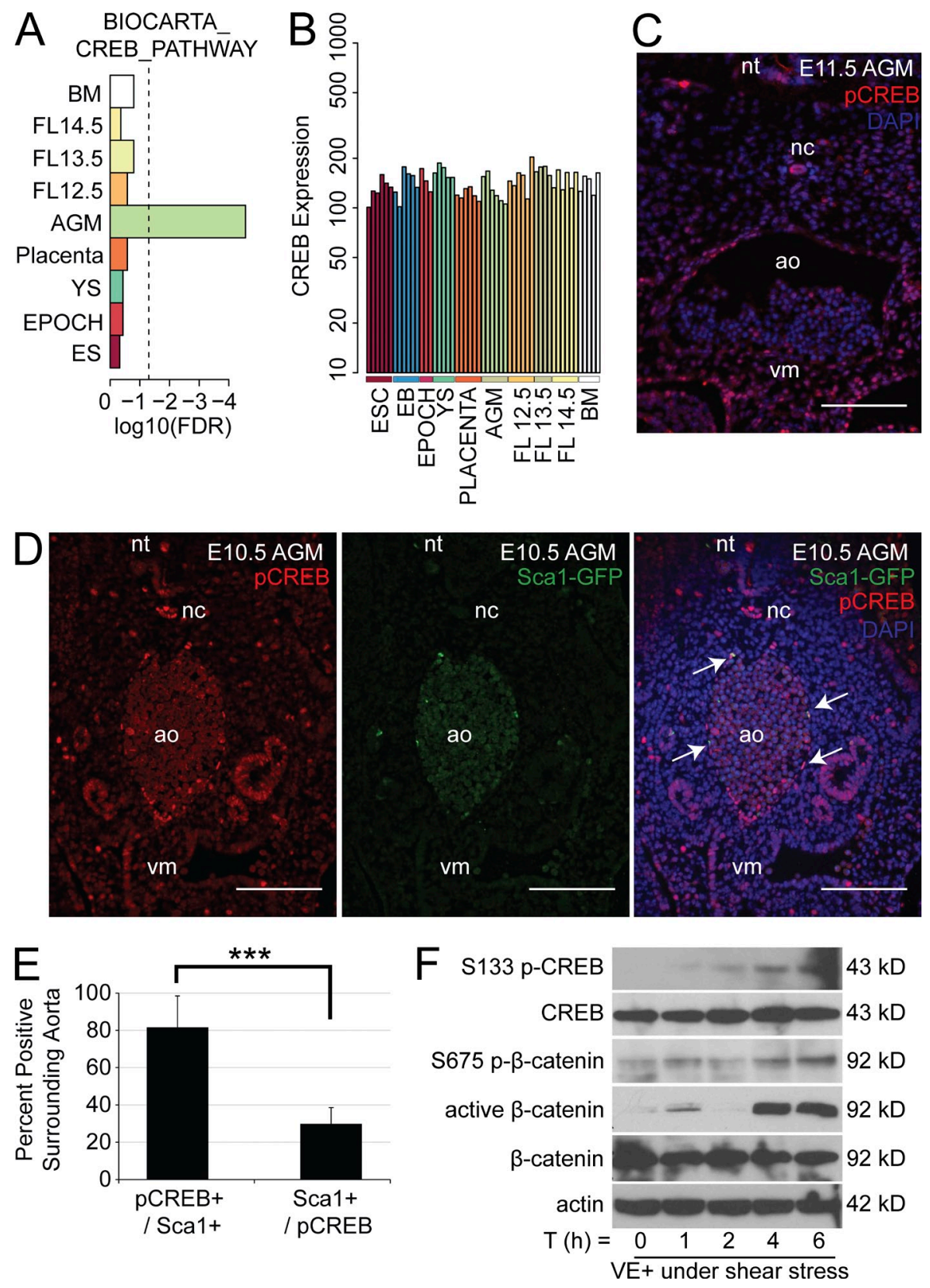

Figure 1. Phosphorylated CREB is present in the AGM and increased by shear stress. (A) Gene set enrichment analysis for CREB target genes using the two-sample Kolmogorov-Smirnov test comparing each hematopoietic tissue against an ESC-derived embryoid body (EB). FL, fetal liver; YS, yolk sac; EPOCH, HoxB4 induced. Data are from McKinney-Freeman et al. (2012; GSE37000). (B) Expression of CREB across various hematopoietic tissues. (C) Immunofluorescence section of E11.5 AGM showing the localization of phospho-CREB (pCREB) in the cells lining the endothelium and ventral mesenchyme. ao, dorsal aorta; nc, notochord; nt, neural tube, vm, ventral mesenchyme. Bar, $100 \mu \mathrm{m}$. (D) Immunofluorescence section of E10.5 AGM showing the localization of pCREB and Sca1-GFP. ao, dorsal aorta; nc, notochord; nt, neural tube, vm, ventral mesenchyme. Arrows indicate double positive cells. Bars, $100 \mu \mathrm{m}$. (E) Quantification of pCREB ${ }^{+}$in Sca $1^{+}$population and Sca $1^{+}$in pCREB ${ }^{+}$population in cells lining the dorsal aorta. $n=5$. (F) Immunoblot of VE-cadherin ${ }^{+}$ cells from differentiated $m E S C s$ that were exposed to shear stress for $6 \mathrm{~h}$.
The top CREB co-occupants within promoters of genes upregulated by CREB overexpression included PLU.1, THAP1, MYC, CEBPD, E2F4, and SMAD1 (Fig. 2 B). Among these top hits were two direct effectors of BMP signaling. SMAD1 is a direct target of BMP receptors and is responsible for their downstream transcriptional activity (Kretzschmar et al., 1997), and E2F4 is known to be a SMAD cofactor (Chen et al., 2002). Therefore, we investigated the interaction between CREB and the BMP pathway target SMAD1.

As this analysis was restricted to genes responding to CREB overexpression, we also analyzed global genomic occupancy in active promoters and enhancers. SMAD1 and CREB peaks were enriched near active promoters (Fig. 2 C). Active enhancers are defined by the presence of $\mathrm{H} 3 \mathrm{~K} 4$ monomethylation (H3K4me1) and $\mathrm{H} 3 \mathrm{~K} 27 \mathrm{ac}$ marks in the absence of H3K4me3 (Creyghton et al., 2010). CREB bound active enhancers less than promoters, which is in agreement with the preferential promoter distribution of CREB in other cell types (Fig. 2 D; Zhang et al., 2005). However, SMAD1 still overlapped these CREB enhancer peaks (Fig. 2 D). To investigate the biological function of the genes co-bound by both CREB and SMAD1, we analyzed the top 3,000 genes with the strongest enrichment for CREB and SMAD1 peaks for PANTHER pathway annotation (Mi et al., 2007). Genes of co-bound peaks were annotated for hematopoietic cell activation, angiogenesis, and VEGF signaling pathway (Fig. 2 E). To strengthen our claim regarding CREB and SMAD1 genomic co-occupancy, we treated K562 cells with forskolin 

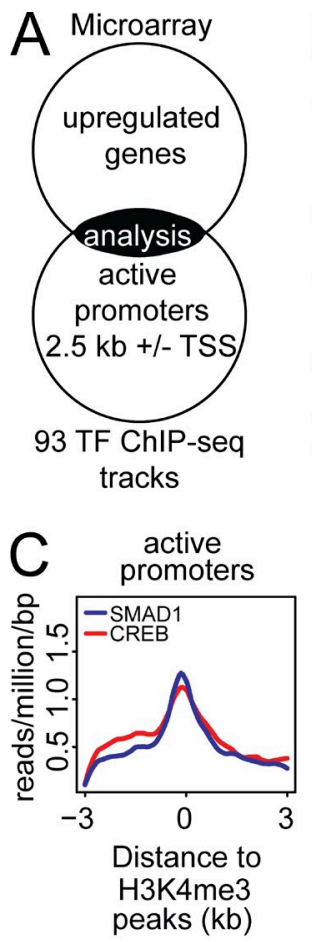
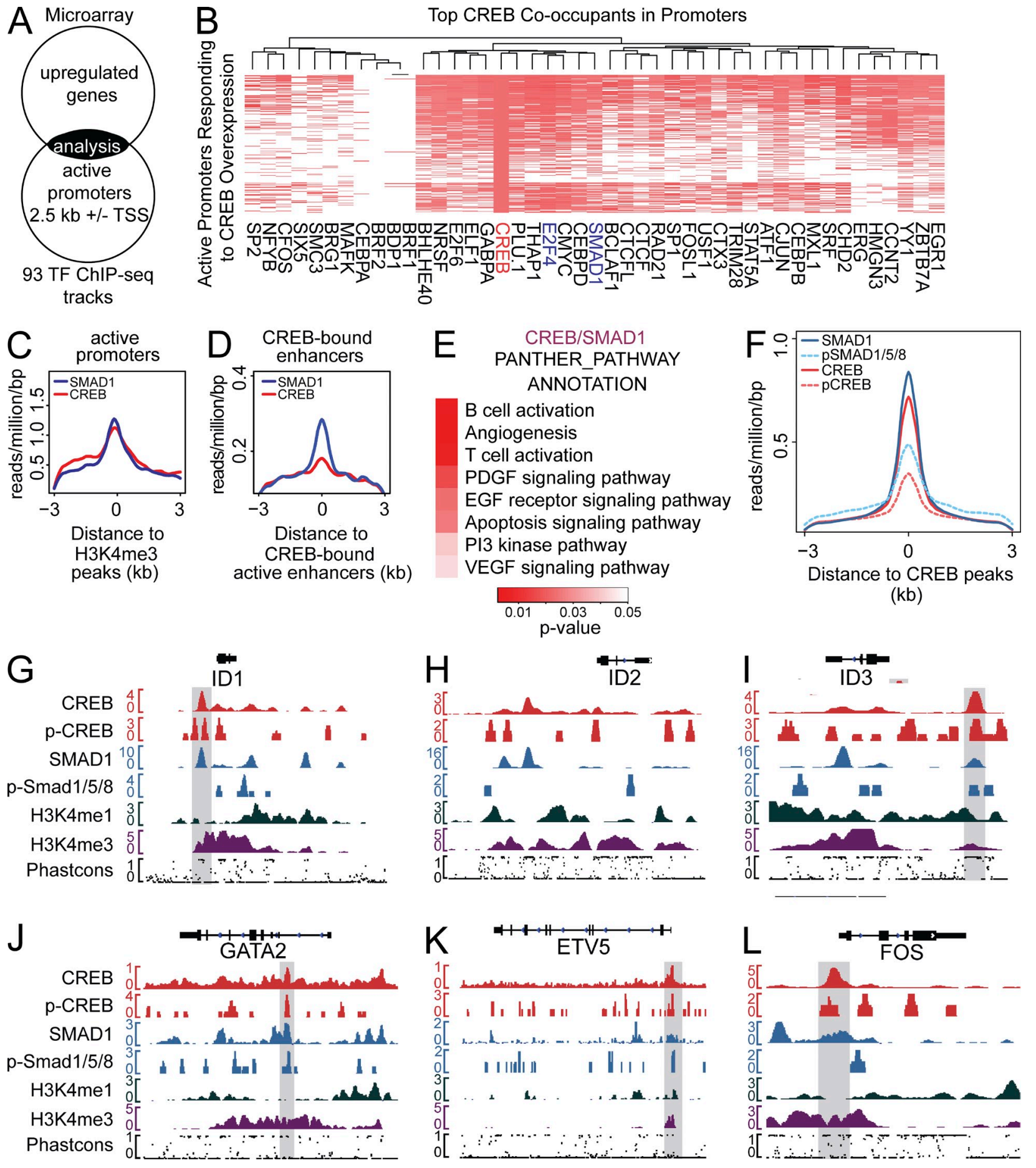

Figure 2. Genomic interaction of CREB and SMAD1 in K562 cells. (A) Experimental schema showing the strategy for analysis of CREB-overexpression and genomic occupancy. (B) Top two quartiles of top CREB co-occupants in promoters of genes responding to CREB overexpression. Rows indicate genes up-regulated by CREB-overexpression and columns indicate binding of TFs. (C) Global CREB and SMAD1 promoter co-occupancy at active promoters. (D) SMAD1 co-occupancy at CREB-bound enhancers. (E) Annotation of top 3,000 scoring CREB and SMAD1 co-bound genes using PANTHER PATHWAY annotation. (F) Validation of CREB and SMAD1 genomic occupancy with phospho-CREB and phospho-Smad1/5/8 ChIP-seq. Genomic view of CREB and SMAD1 binding in the (G) ID1, (H) ID2, (I) ID3, (J) GATA2, (K) ETV5, and (L) FOS gene region. Phastcons track shows species conservation between 46 species. 
or BMP and performed ChIP-sequencing using phosphoCREB or phospho-Smad1/5/8 antibodies and obtained similar results (Fig. 2 F). Although K562 is a committed hematopoietic cell, the co-bound regions raise the hypothesis that these pathways regulate both hematopoietic and endothelial genes.

We explored this hypothesis further in the context of specific genes. First, we examined CREB and SMAD1 occupancy of early BMP response genes of the pathway ID1-3, some of which have known roles in vasculogenesis (Lyden et al., 1999). In the genomic region containing these genes, we found binding of both CREB and SMAD1 in the promoters (marked by H3K4me3) and enhancers (marked by H3K4me1) in highly conserved regions (Fig. 2, G-I). In addition to the early response genes, we also a observed similar co-occupancy within the GATA2 promoter (Fig. $2 \mathrm{~J}$ ), a known regulator of AGM hematopoiesis (Ling et al., 2004); ETV5 (Fig. 2 K), which is expressed in the AGM HSCs (McKinney-Freeman et al., 2012); and FOS (Fig. 2 L), which was shown recently in cooperation with Gata2, Etv6, and Gfi1b to be sufficient to convert fibroblasts to endothelial cells capable of giving rise to hematopoietic cells (Pereira et al., 2013). Collectively, this bioinformatics screen suggests that the PKA-CREB and BMP pathways interact in the AGM, where emerging hematopoietic cells have endothelial characteristics (North et al., 2002).

\section{BMP4 rescues AGM hematopoiesis from PKA-CREB inhibition}

We investigated the interaction between the PKA-CREB and BMP pathways during AGM hematopoiesis, as predicted by bioinformatics, by examining the localization of the BMP ligand Bmp4 in the E11.5 AGM. Similar to the distribution of phospho-CREB (Fig. 1, C and D), Bmp4 was localized in cells lining the dorsal aorta and, more strongly, in the ventral than the dorsal mesenchyme, as previously reported (Fig. 3 A; Durand et al., 2007). In immediately adjacent sections, the transcriptionally active BMP target protein complexes phosphoSmad1/5 and Smad1/5/8 showed a similar distribution (Fig. 3, $\mathrm{B}$ and $\mathrm{C})$. Upon closer examination of the ventral floor of the dorsal aorta, we observed cells with phospho-CREB in close proximity to Bmp4 (Fig. 3 D).

To directly modulate the PKA-CREB pathway within embryonic tissues, we dissected the AGM from E11.5 embryos and isolated VE-cadherin ${ }^{+}$cells (Fig. 3 E) - a fraction known to harbor HSCs (North et al., 2002) —and exposed these cells to chemical modulators or extracellular ligands. Using high-content immunofluorescence, we tracked the dynamics of pathway modulation by quantifying the nuclear localization of proteins at a single cell level using VEcadherin $^{+}$cells isolated from differentiating mESCs. Exposure of these cells to KT5720, a potent inhibitor of PKA through competitive inhibition of ATP, reduced phospho-CREB in a dose-dependent fashion most strongly at $1 \mathrm{~h}$ after treatment (Fig. 3 F). Exposure to $5 \mu \mathrm{M}$ of KT5720 significantly reduced CFU activity of VE-cadherin ${ }^{+}$cells isolated from the E11.5
AGM (Fig. 3 G). In support of a PKA-CREB-BMP signaling interaction, BMP 4 treatment of $4 \mathrm{ng} / \mathrm{ml}$ rescued hematopoietic CFUs when PKA-CREB was inhibited (Fig. 3 G). We obtained similar results when we repeated the experiment with E10.5 AGM (Fig. $3 \mathrm{H}$ ). However, when we treated VEcadherin $^{-}$cells, which includes $\mathrm{CD} 41^{+} / \mathrm{CD} 45^{+}$hematopoietic precursors (North et al., 2002; Kim et al., 2013), the treatment had no effect, suggesting that the effect is specific to VE-cadherin ${ }^{+}$cells (Fig. 3 I). Because KT5720 has nonspecific targets in addition to its effect on PKA, we used another PKA inhibitor, H89, which has no other overlapping nonspecific targets, and found similar effects $(0.5-2 \mu \mathrm{M}$; unpublished data; Davies et al., 2000). Rescue of hematopoietic CFUs suggests that BMP4 acts downstream of PKA-CREB signaling in ex vivo culture.

To assess the hematopoietic function of PKA-CREB in vivo, we transplanted isolated E11.5 VE-cadherin ${ }^{+}$cells that were exposed to chemical compounds or ligands into lethally irradiated adult recipients. We monitored donor chimerism based on the percentage of CD $45.2^{+}$donor cells and assessed lineage contribution based on $\mathrm{Gr}^{+} / \mathrm{Mac}^{+}$myeloid cells, $\mathrm{CD}^{+} \mathrm{T}$ cells, and B220 ${ }^{+} \mathrm{B}$ cells (Fig. $3 \mathrm{~J}$ ). Exposure to $5 \mu \mathrm{M}$ of KT5720 reduced the percentage of donor chimerism as compared with the DMSO-treated controls (Fig. $3 \mathrm{~K}$ ). Alternatively, BMP4 treatment rescued the percentage of donor chimerism from PKA-CREB inhibition (Fig. 3 K). These results suggest that PKA-CREB is required for in vivo hematopoietic activity and that BMP4 can compensate for the inhibition of PKA-CREB.

\section{Smad signaling is correlated with PKA-CREB activation}

We explored the temporal dynamics of PKA-CREB and BMP signaling activation to investigate a link between these pathways. We used high-content immunofluorescence to quantify the levels of phospho-CREB and phospho-Smad1/5/8 on a single-cell level over time using VE-cadherin ${ }^{+}$cells from differentiating mESCs. Activation of the PKA-CREB pathway using forskolin, an adenylyl cyclase activator, increased phospho-CREB in a dose-dependent manner (Fig. 4 A). When we quantified phospho-Smad1/5/8 over time in forskolin-treated cells, we saw an increase concomitant with an increase in phospho-CREB (Fig. 4 B). Both doses of forskolin increased phospho-Smad1/5/8 at $2 \mathrm{~h}$ after treatment, with the higher dose downtrending toward $8 \mathrm{~h}$ and the lower dose uptrending. When compared with BMP4-treated cells, phospho-Smad1/5/8 in forskolin-treated cells displayed distinct temporal dynamics. Collectively, phospho-Smad1/5/8 dynamics correlate with that of phospho-CREB.

\section{Forskolin treatment promotes AGM hematopoiesis}

In the absence of exogenous BMP ligands in culture, the presence of phospho-Smad1/5/8 in forskolin-treated cells suggests that PKA-CREB activates the BMP pathway to promote AGM hematopoiesis. We treated VE-cadherin ${ }^{+}$ cells from the E11.5 AGM with forskolin and observed a significant increase in the number and size of multipotent 

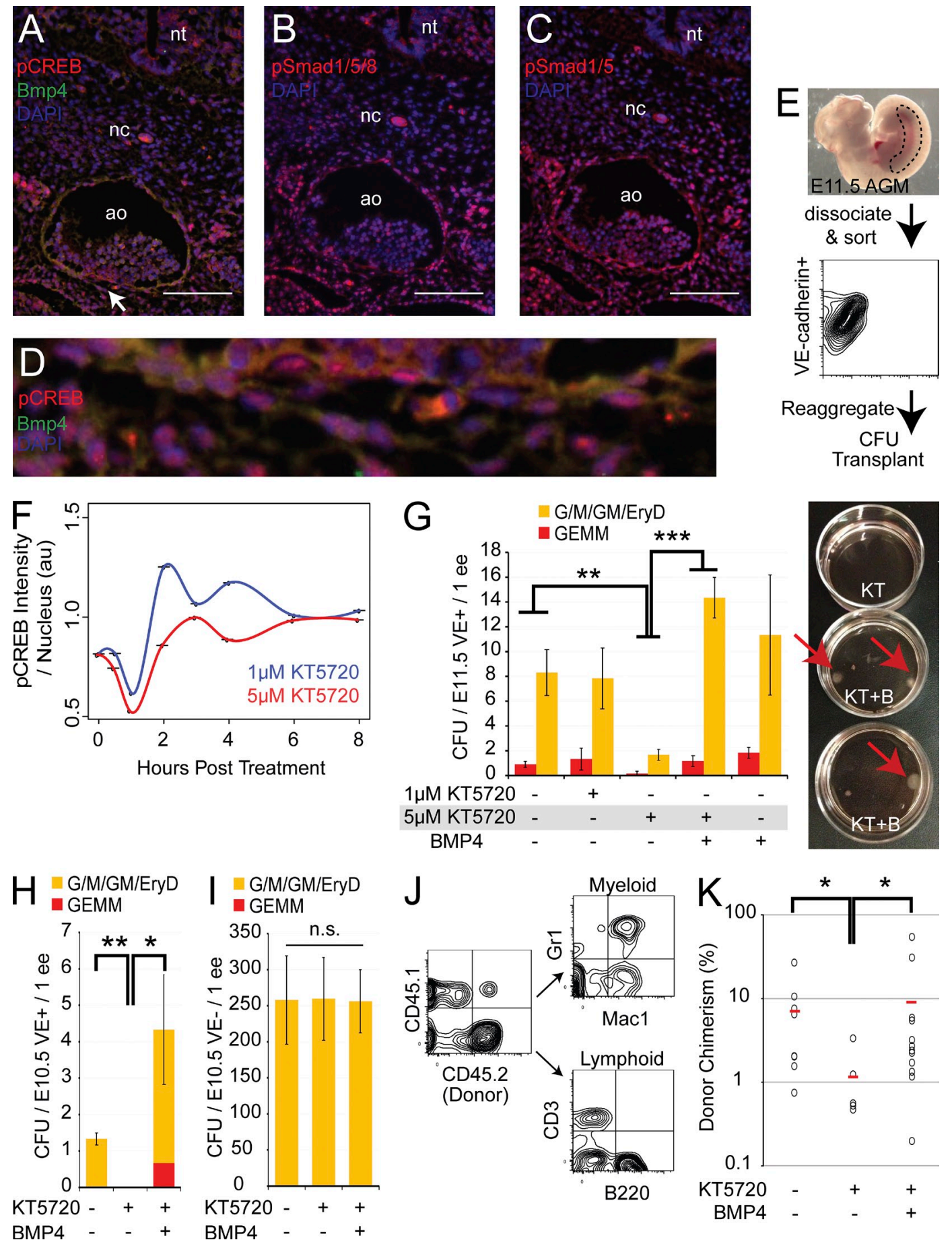

Figure 3. BMP4 rescues hematopoiesis from PKA-CREB inhibition. (A) Immunofluorescence section of the E11.5 AGM showing the co-localization of phospho-CREB and Bmp4. ao, dorsal aorta; nc, notochord; nt, neural tube. (B) Immunofluorescence of adjacent section to A showing the localization of phospho-Smad1/5/8. (C) Immunofluorescence of adjacent section to A showing the localization of phospho-Smad1/5. (D) Zoomed view of the ventral mesenchyme indicated by an arrow in A. (E) Experimental scheme for working with AGM-derived VE-cadherin+ cells. (F) Normalized high-content immunofluorescence of the phospho-CREB dynamics upon KT5720 treatment over 8 h. $n=2$. (G) CFU of sorted VE-cadherin+ cells from E11.5 per embryo equivalent (e.e) treated with various compounds for $8 \mathrm{~h}$. Representative multipotent CFUs at $12 \mathrm{~d}$ after plating shown on right. $n=3-5$. (H) CFU assay of sorted VE-cadherin+ cells from E10.5 per e.e treated with various compounds for 8 h. $n=3$. (I) CFU assay of sorted VE-cadherin ${ }^{-}$cells from E10.5 per e.e treated with various compounds for 8 h. $n=3$. (J) Example of peripheral blood analysis for donor chimerism for myeloid and lymphoid cell contribution using flow cytometry. (K) Donor chimerism levels at 12-wk after transplantation. 2.5 e.e. were used per recipient. Averages are shown in red. One-sided Wilcoxon rank-sum test was performed on log-transformed values. Bars: (A-C) $100 \mu \mathrm{m}$. 


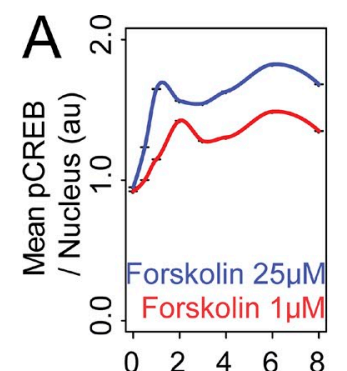

Hours Post Treatment

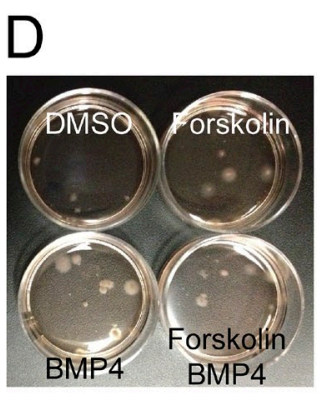

\section{BMP4}

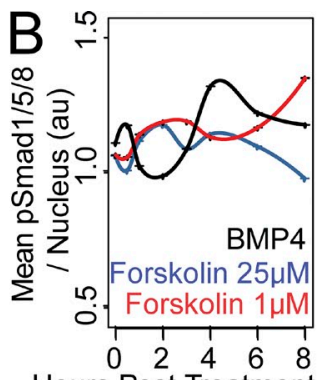

Hours Post Treatment
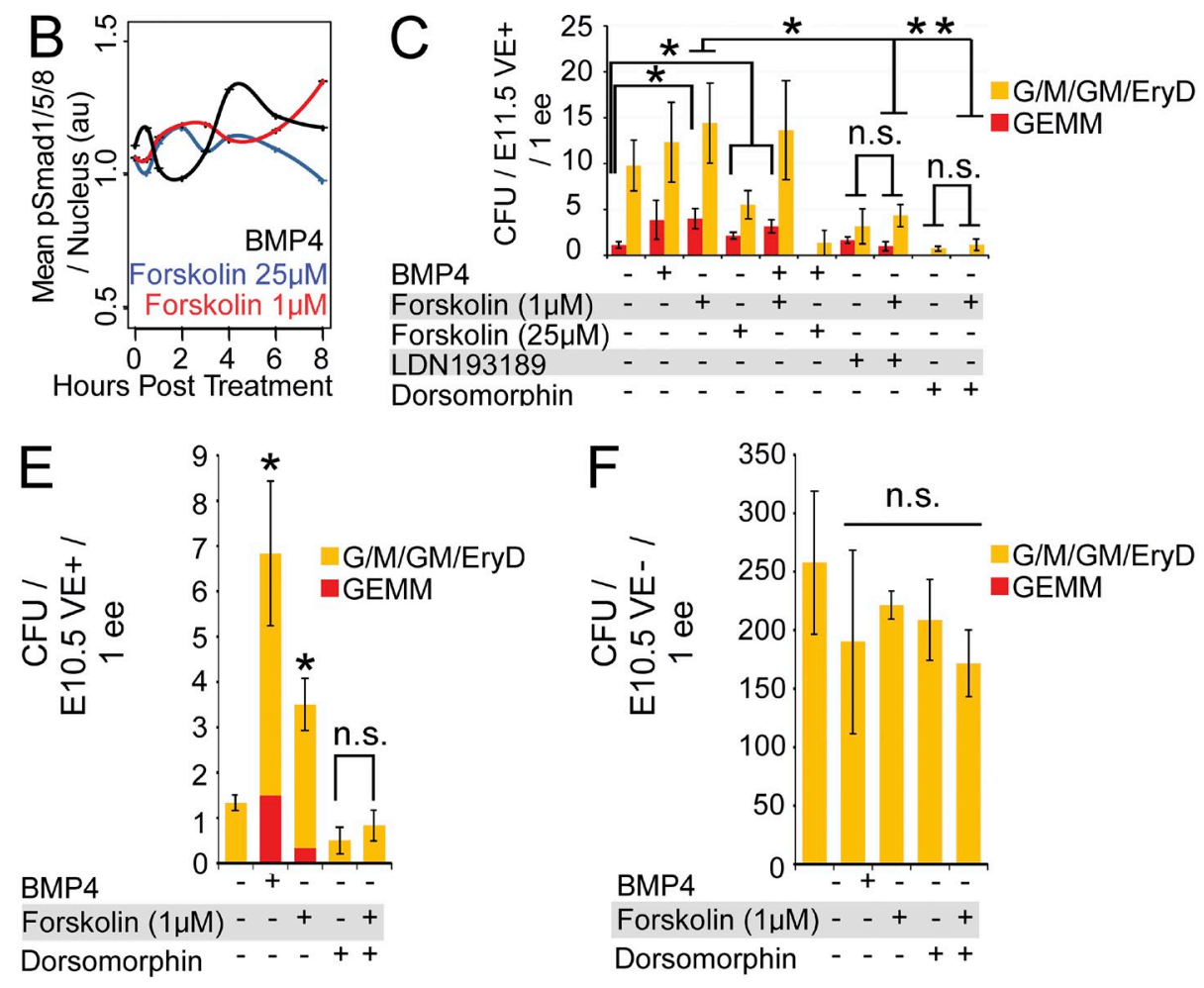

G
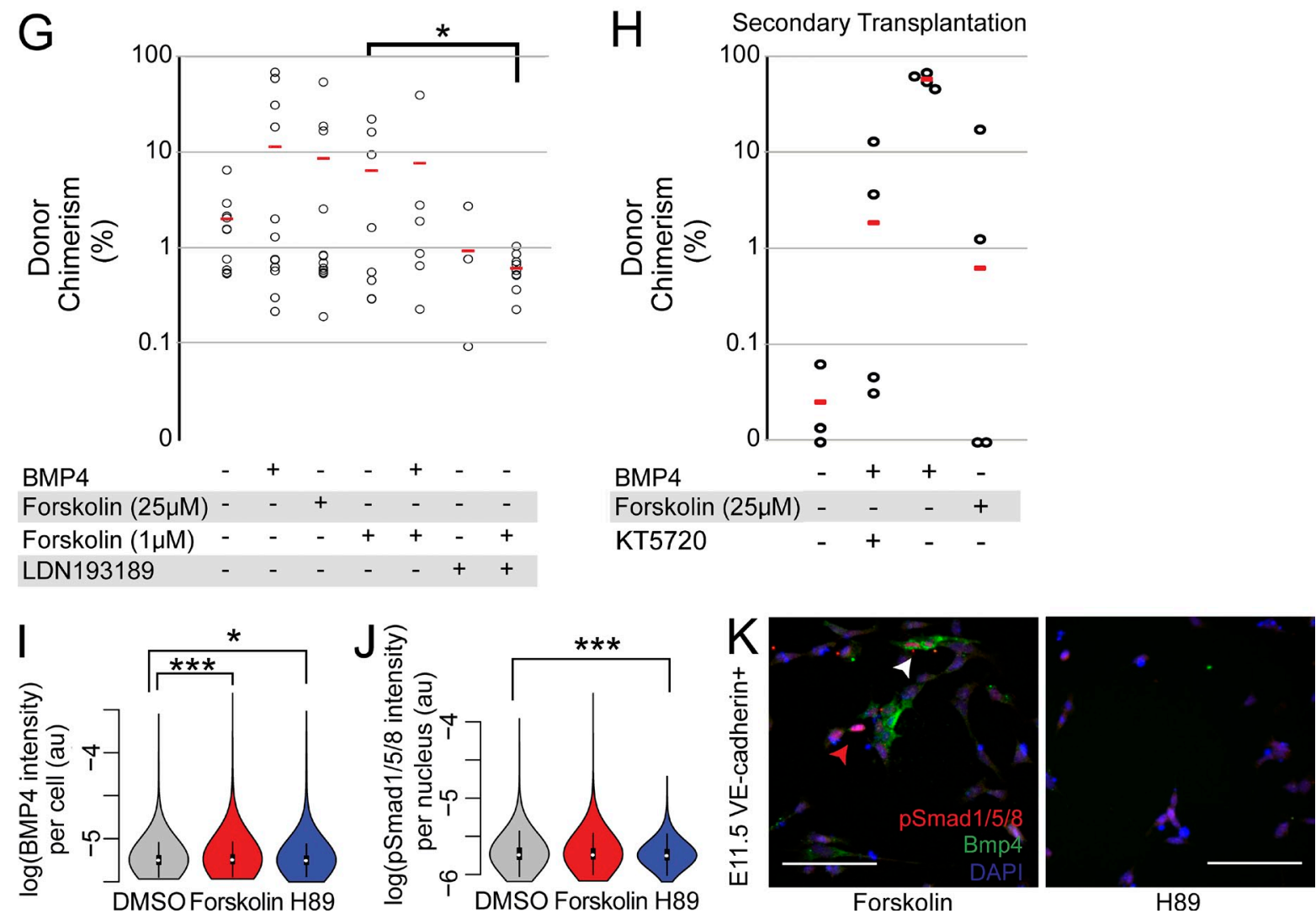

Figure 4. Prohematopoietic effect of forskolin is dependent on BMP type I receptors. (A) Normalized high-content immunofluorescence of the phospho-CREB dynamics upon forskolin treatment over 8 h. $n=2$. (B) Normalized high-content immunofluorescence of the phospho-Smad1/5/8 dynamics upon forskolin or BMP4 treatment over $8 \mathrm{~h} . n=2$. (C) CFU assay of sorted VE-cadherin+ cells per embryo equivalent (e.e) treated with various compounds for $8 \mathrm{~h}$ before assay. $n=3-9$. (D) Representative multipotent CFUs from C at $12 \mathrm{~d}$ after plating. (E) CFU assay of sorted VE-cadherin ${ }^{+}$cells from E10.5 per e.e treated with various 
GEMM colonies (Fig. 4, C and D), whereas lineage-restricted colonies were less affected. We also observed a similar trend with BMP4 treatment, but the result was not significant (Fig. $4 \mathrm{C} ; \mathrm{P}=0.2$ ). Both forskolin and BMP4 treatments have similar prohematopoietic effects on CFUs.

To assess whether PKA-CREB activation collaborates with pathways independent of BMP to promote hematopoiesis, we combined BMP4 and forskolin treatments. If forskolin activates hematopoietic pathways other than BMP, then the combination treatment should increase CFUs above that of forskolin treatment alone. However, $1 \mu \mathrm{M}$ forskolin combined with BMP4 did not result in additional enhancement (Fig. 4 C). The higher dose of forskolin combined with BMP4 had an inhibitory effect on CFUs when compared with the control (Fig. 4 C), suggesting dose-sensitivity, possibly due to the role of BMP as a concentration-dependent morphogen.

Activation of adenylate cyclase can result in activation of Epac1/2 in addition to PKA (de Rooij et al., 1998) but Epac1 and Epac2 expression were absent in the AGM (unpublished data). Moreover, forskolin treatment did not result in activation of the Epac target pathway phospholipase C-epsilon (unpublished data), thus excluding its role in AGM hematopoiesis.

Because CREB activation drives antiapoptotic signals through induction of $b c l-2$ expression in B cells (Wilson et al., 1996), we examined the effect of forskolin or BMP4 treatment on the viability of AGM VE-cadherin ${ }^{+}$cells. Cells exposed to forskolin or BMP4 did not have significant changes in the percentage of apoptotic cells compared with the control, as assessed by Annexin V staining (unpublished data). Therefore, it is unlikely that the increase in hematopoiesis is caused by increased cell survival.

BMP4 treatment is known to expand the c-Kit low fraction of AGM cells in culture (Marshall et al., 2007). If forskolin treatment induces the BMP pathway, then forskolin exposure should induce a similar surface phenotype as BMP4 exposure. Accordingly, forskolin treatment resulted in a modest trend toward an increase in c-Kit low fraction that is comparable to BMP4 treatment alone (unpublished data).

$\mathrm{HSC}$ reside in the $\mathrm{VE}$-cadherin ${ }^{+} \mathrm{CD} 45^{+}$fraction of the E11.5 AGM (North et al., 2002). We tested whether the forskolin or BMP4 treatment of AGM VE-cadherin ${ }^{+}$cells increases the absolute number of $\mathrm{VE}-$ cadherin ${ }^{+} \mathrm{CD} 45^{+}$cells. However, we did not observe any significant increase in these cells with forskolin treatment (unpublished data). This suggests that there is not an appreciable change in the number of phenotypic HSCs, but rather a detectable change in HSC functionality.

\section{Prohematopoietic effect of forskolin is dependent on BMP type I receptors}

Because genomic CREB-binding sites overlap with SMAD1 sites (Fig. 2, B and F), we explored whether forskolin activated SMAD1 target genes directly through CREB or whether the effect was dependent on the secretion of a BMP ligand. To test this, we used two different but specific BMP type I receptor ALK2/3/6 inhibitors LDN193189 and dorsomorphin (Yu et al., 2008a,b). In agreement with previous studies on BMP signaling (Durand et al., 2007; Wilkinson et al., 2009), $10 \mu \mathrm{M}$ dorsomorphin significantly reduced the hematopoietic CFUs compared with the control (Fig. 4 C). $4 \mu \mathrm{M}$ LDN193189 showed a trend toward reduced hematopoietic activity but was not significant (Fig. 4 C; $\mathrm{P}=0.11$ ). When forskolin treatment was combined with LDN193189 or dorsomorphin, CFU activity was significantly diminished as compared with the forskolin treatment alone (Fig. 4 C). Additionally, CFU activity from the combination treatments was similar to inhibitor treatments alone. A similar result was obtained when we repeated the experiment with E10.5 AGM (Fig. 4 E). When we treated VE-cadherin ${ }^{-}$cells, which includes CD $41^{+} / \mathrm{CD} 45^{+}$hematopoietic cells, the treatment had no effect, confirming that the effect is specific to VE-cadherin ${ }^{+}$cells (Fig. 4 F).Together, these data suggest that the prohematopoietic effect of forskolin is dependent on BMP type I receptors.

To confirm this with in vivo transplantation experiments, we sortedVE-cadherin ${ }^{+}$cells from the E11.5 AGM and treated with forskolin, BMP4 ligand, or an inhibitor of the BMP type I receptor LDN193189. We then transplanted these treated cells into irradiated recipients and monitored donor chimerism. In agreement with the CFU data, forskolin and BMP4 showed a trend toward increased hematopoietic engraftment, and the combination treatment did not result in an additional increase in chimerism (Fig. 4 G). Multilineage engraftment upon secondary transplantation confirmed the long-term potential of these HSCs (Fig. $4 \mathrm{H}$ ). Moreover, hematopoietic engraftment was modestly decreased with the inhibition of BMP type I receptors (Fig. 4 G), confirming a ligand-dependent effect on engraftment. Curiously, some LDN193189-treated samples engrafted, suggesting that BMP signaling may be required for specification of HSCs but not thereafter (Fig. $4 \mathrm{G}$ ).

compounds for 8 h. $n=3$. (F) CFU assay of sorted VE-cadherin- cells from E10.5 per e.e treated with various compounds for 8 h. $n=3$. (G) Donor chimerism levels at $12 \mathrm{wk}$ after transplantation. Averages are shown in red. One-sided Wilcoxon rank-sum test was performed on log-transformed values. $(\mathrm{H})$ Donor chimerism levels at 12-16 wk after secondary transplantation from top 4 engrafted recipients from Figs. 3 I and 4 E. Averages are shown in red. (I) Violin plots showing the quantification of BMP4 via immunofluorescence upon forskolin or $\mathrm{H} 89$ treatment in VE-cadherin ${ }^{+}$cells isolated from the E11.5 AGM. Significance was assessed using the two-sided Wilcoxon-rank sum test. (J) Violin plots showing the quantification of phospho-Smad1/5/8 via immunofluorescence upon forskolin or H89 treatment of VE-cadherin ${ }^{+}$cells isolated from the E11.5 AGM. Significance was assessed via the two-sided Wilcoxon-rank sum test. (K) Immunofluorescence for Bmp4 and phospho-Smad1/5/8 in VE-cadherin+ cells isolated from the E11.5 AGM and treated with forskolin or H89. Red arrowhead, phospho-Smad1/5/8 near a Bmp4 secreting cell. White arrowhead, Phospho-Smad1/5/8 in the same cell secreting Bmp4. Bars, $50 \mu \mathrm{m}$. 

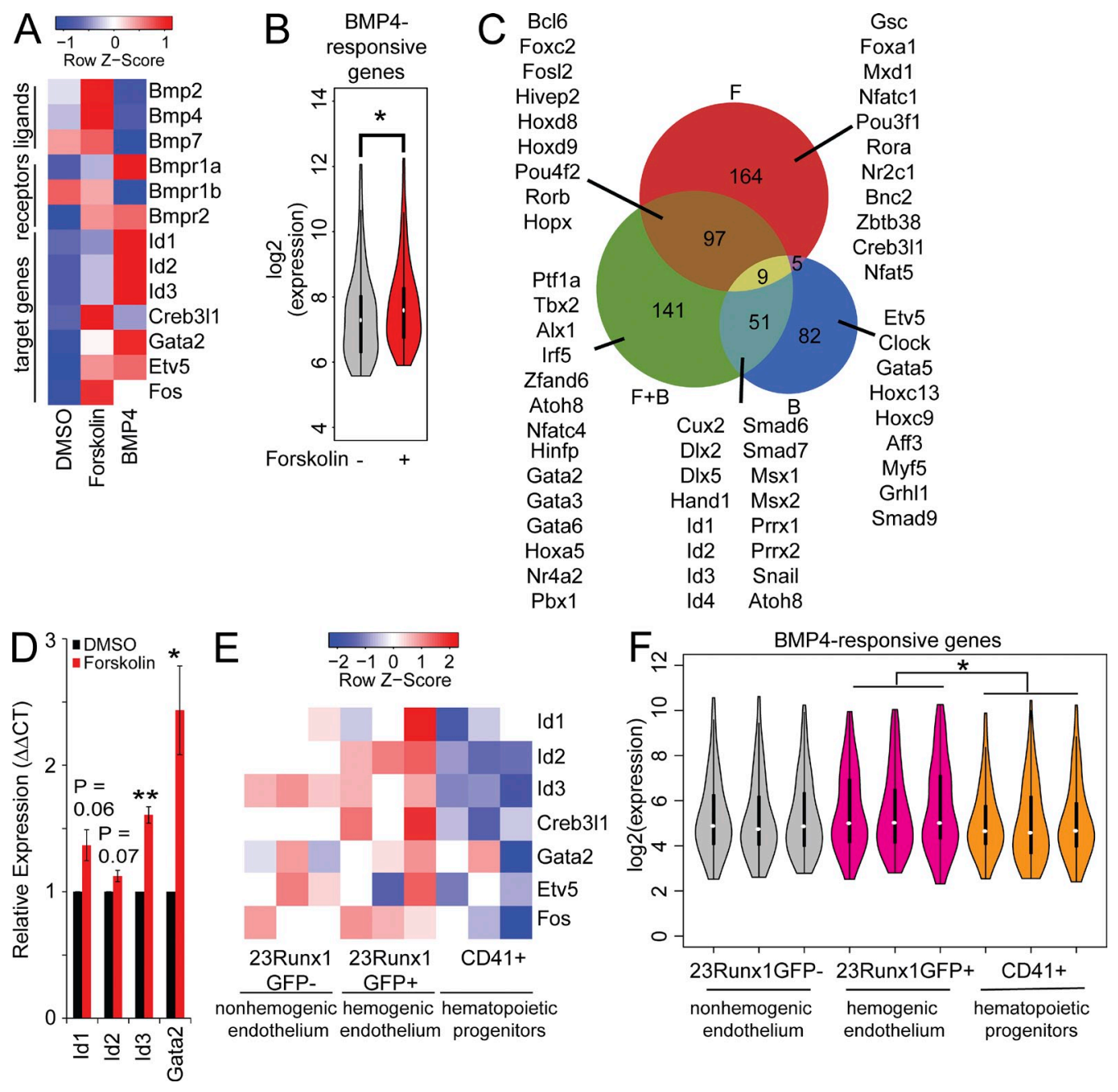

Figure 5. Transcriptome analysis reveals evidence of PKA-CREB-BMP signaling in VE-cadherin+ cells. (A) Up-regulation of BMP ligands and target genes upon forskolin treatment. $n=2$. (B) Violin plot of BMP4-responsive target genes that are detectable via presence/absence calls upon forskolin treatment. Statistical significance via the two-sided Wilcoxon-rank test. $n=2$. (C) Transcription factors significantly up-regulated by each treatment ( $F$, forskolin; B, BMP4). Numbers indicate significantly up-regulated genes. $n=2$. (D) Quantitative RT-PCR on selected BMP target genes /d 1-3 and Gata2 upon forskolin treatment. $n=4$. (E) Selected CREB and BMP target genes analyzed in the nonhemogenic endothelium, hemogenic endothelium, and hematopoietic progenitors (GSE52075; Swiers et al., 2013). $n=3$. (F) Violin plot of BMP4 target genes similar to B) in the nonhemogenic endothelium, hemogenic endothelium and hematopoietic progenitors (GSE52075; Swiers et al., 2013). Statistical significance via the two-sided Wilcoxon-rank test. $n=3$.

Although the hematopoietic effect of forskolin was dependent on the BMP type I receptors, the source of BMP ligands was unknown because serum-free media was used to culture VE-cadherin ${ }^{+}$cells. We hypothesized that sorted VEcadherin ${ }^{+}$cells are able to release Bmp ligands and signal to otherVE-cadherin ${ }^{+}$cells via paracrine or autocrine signaling. To confirm this, we sortedVE-cadherin ${ }^{+}$cells from the AGM and quantified Bmp4 ligand release via high-content immunofluorescence after PKA-CREB activation with forskolin. Bmp4 secretion per cell was significantly increased with forskolin treatment (Fig. 4 I). Conversely, inhibition of PKA-CREB signaling via the H89 compound decreased Bmp4 secretion (Fig. 4 I), as well as the BMP target phospho-Smad1/5/8 (Fig. $4 \mathrm{~J}$ ). We found instances of phospho-Smad1/5/8 in
VE-cadherin ${ }^{+}$cells near cells secreting the Bmp4 ligand and phospho-Smad1/5/8 in Bmp4-secreting cells, indicative of both autocrine and paracrine signaling (Fig. $4 \mathrm{~K}$ ).

\section{Global transcriptome shift demonstrating BMP pathway activation}

To confirm the BMP pathway activation via microarray analysis, we evaluated gene expression changes in forskolin or BMP4-treated VE-cadherin ${ }^{+}$cells from the AGM. First we investigated whether forskolin-treated cells up-regulated BMP ligands. Indeed, forskolin modestly up-regulated Bmp2/4, which are both ligands of the BMP type I receptors (Fig. $5 \mathrm{~A}$ ). The expression of the BMP type I receptors Bmpr1a or Bmpr1b were not altered when compared with the control consistent 
with a ligand-dependent effect (Fig. 5 A). Forskolin treatment also up-regulated genes co-bound by CREB and SMAD1 (Fig. 2, G-L) but the effect was less prominent than BMP4 treatment alone (Fig. 5 A).

Because the effect of forskolin on selected BMP targets was weaker than BMP4, we assessed whether we could detect a global up-regulation in BMP target genes in the forskolintreated cells. BMP4 treatment significantly up-regulated 147 genes ( $\mathrm{p}$-value cut-off, 0.01). Forskolin-treated cells also had a significant global up-regulation in these BMP target genes that are present (Fig. $5 \mathrm{~B} ; \mathrm{P}=0.02$ ), thus confirming that PKA-CREB activation results in global BMP target gene up-regulation.

Given the up-regulation of the BMP target genes, we expected an overlap in the hematopoietic transcription factors significantly up-regulated by forskolin or BMP4 treatment. Surprisingly, there was no overlap of up-regulated transcription factors (Fig. $5 \mathrm{C}$ ). We hypothesized that this was due to the short duration of treatment that resulted in up-regulation of genes below the significance threshold. To test this further, we examined the genes up-regulated by the combination treatment of forskolin and BMP4 and found a stronger activation of factors important for AGM HSC formation, such as Gata2 (Creyghton et al., 2010) and Gata3 (Fitch et al., 2012), as well as factors important for adult HSC maintenance such as Pbx1 (Ficara et al., 2008) compared with either treatment alone (Fig. 5 C).

Finally, we confirmed the up-regulation of several BMP target genes (Id1, Id3, and Gata2) upon forskolin treatment by quantitative RT-PCR (Fig. 5 D). Together, these data suggest that forskolin and BMP4 up-regulate common BMP targets, including those with known roles in hematopoiesis.

\section{CREB-BMP in the hemogenic endothelium}

To confirm the activity of CREB-BMP signaling in the hemogenic endothelium, we analyzed published microarray data on the hemogenic endothelium characterized using the Runx1+23 enhancer-GFP transgenic mice (Swiers et al., 2013). At the onset of circulation, both the hemogenic endothelium and nonhemogenic endothelium up-regulated selected CREB-BMP targets, whereas hematopoietic progenitors did not (Fig. 5 E). Global BMP target up-regulation was significantly increased only in the hemogenic endothelium as compared with the hematopoietic progenitors but not in the nonhemogenic endothelium (Fig. 5 F). Together with the immunostaining and CFU data (Figs. 1 D, 3 I, and 4 F), this suggests that hemogenic endothelial cells respond to CREBBMP signaling but hematopoietic progenitors do not.

\section{Shear stress dependence of the CREB-BMP signaling axis} We hypothesized that the PKA-CREB-BMP signaling axis is a blood-flow dependent pathway because phospho-CREB in VE-cadherin ${ }^{+}$cells increased with shear stress in vitro (Fig. $1 \mathrm{~F}$ ) and because the localization of the factors involved in this signaling axis were expressed close to or within the cells lining the dorsal aorta (Fig. 3 A). To confirm this, we examined
E9.5 murine embryos lacking a heartbeat and intravascular flow due to a homozygous mutation in the $\mathrm{Na}^{+} / \mathrm{Ca}^{2+}$ exchanger Ncx1 (Koushik et al., 2001). These mice are shown to have shear-stress dependent hematopoietic defects at E9.5 in the PSp (Lux et al., 2008; Adamo et al., 2009), which later matures into the AGM.

The embryonic lethality of these mice at E9-10 precludes further analysis of definitive hematopoiesis via transplantation (Medvinsky and Dzierzak, 1996; Koushik et al., 2001). Despite this limitation, we examined histological sections of Ncx1-null embryos to explore the relationship between intravascular flow and the PKA-CREB-BMP signaling axis. In the E9.5 wild type littermates, the two dorsal aortae have fused to a single dorsal aorta, in agreement with previous studies (Fig. 6,A-E; Nagase et al., 2006). Phospho-CREB was present in the mesenchyme surrounding the dorsal aorta, the cells lining the dorsal aorta and the neural tube (Fig. 6 B). In agreement with the E11.5 distribution of phospho-CREB and Bmp4 (Fig. $3 \mathrm{~A}$ ), phospho-CREB and Bmp4 in the E9.5 embryos were also present at higher levels in the ventral mesenchyme surrounding the dorsal aorta (Fig. 6, B and C). In the E9.5 Ncx1-null embryos, we observed a delay in the fusion of the dorsal aortae that occurs between E8-9.5 (Fig. 6, F-J), which is consistent with the growth retardation phenotype previously documented (Koushik et al., 2001). Consistent with the PKA-CREB-BMP axis as a blood flow-responsive pathway, we observed a decrease in phospho-CREB in the mesenchyme surrounding the two dorsal aortae and a stronger decrease in phospho-CREB in the cells lining the dorsal aorta when compared with the neural tube (Fig. 6 G). Bmp4 was similarly decreased but not absent when compared with the control (Fig. 6, H and I). Quantification of phospho-CREB ${ }^{+}$ cells in multiple sections revealed significant decrease with Ncx1 KO embryos (Fig. 6 K). Similar result was obtained with phospho-Smad1/5/8, a BMP target protein (Fig. 6 L).

To determine whether exogenous shear stress can increase PKA-CREB-BMP signaling in the AGM, we sorted VE-cadherin ${ }^{+}$cells from the AGM and subjected them to $6 \mathrm{~h}$ of shear stress. Shear stress increased phospho-CREB levels, and this effect was mitigated by $2 \mu \mathrm{M}$ of H89, a PKA inhibitor (Fig. $6 \mathrm{M}$ ). Furthermore, Bmp4 was detected upon application of shear stress but also decreased with H89 treatment (Fig. $6 \mathrm{M}$ ). BMP4 transcript is found in endothelial cells exposed to shear stress, especially oscillatory shear stress (Fig. $6 \mathrm{~N}$; $\mathrm{Ni}$ et al., 2011). This may be similar to the retrograde flow experienced before formation of cardiac outflow tract cushions and valves at E11.5 and E13.5, respectively (Ji et al., 2003; Vermot et al., 2009).

Finally, we examined whether PKA-CREB-BMP signaling axis can restore the hematopoietic activity in the absence of shear stress. AGM explants from E9.5 Ncx1 KO embryos have reduced hematopoietic progenitor activity in the PSp due to the lack of blood flow (Adamo et al., 2009). When AGM explants from E9.5 Ncx1 KO embryos were exposed to exogenous BMP4 or forskolin $(1 \mu \mathrm{M})$ for $24 \mathrm{~h}$, CFU activity was increased, suggesting a partial rescue via modulation of 

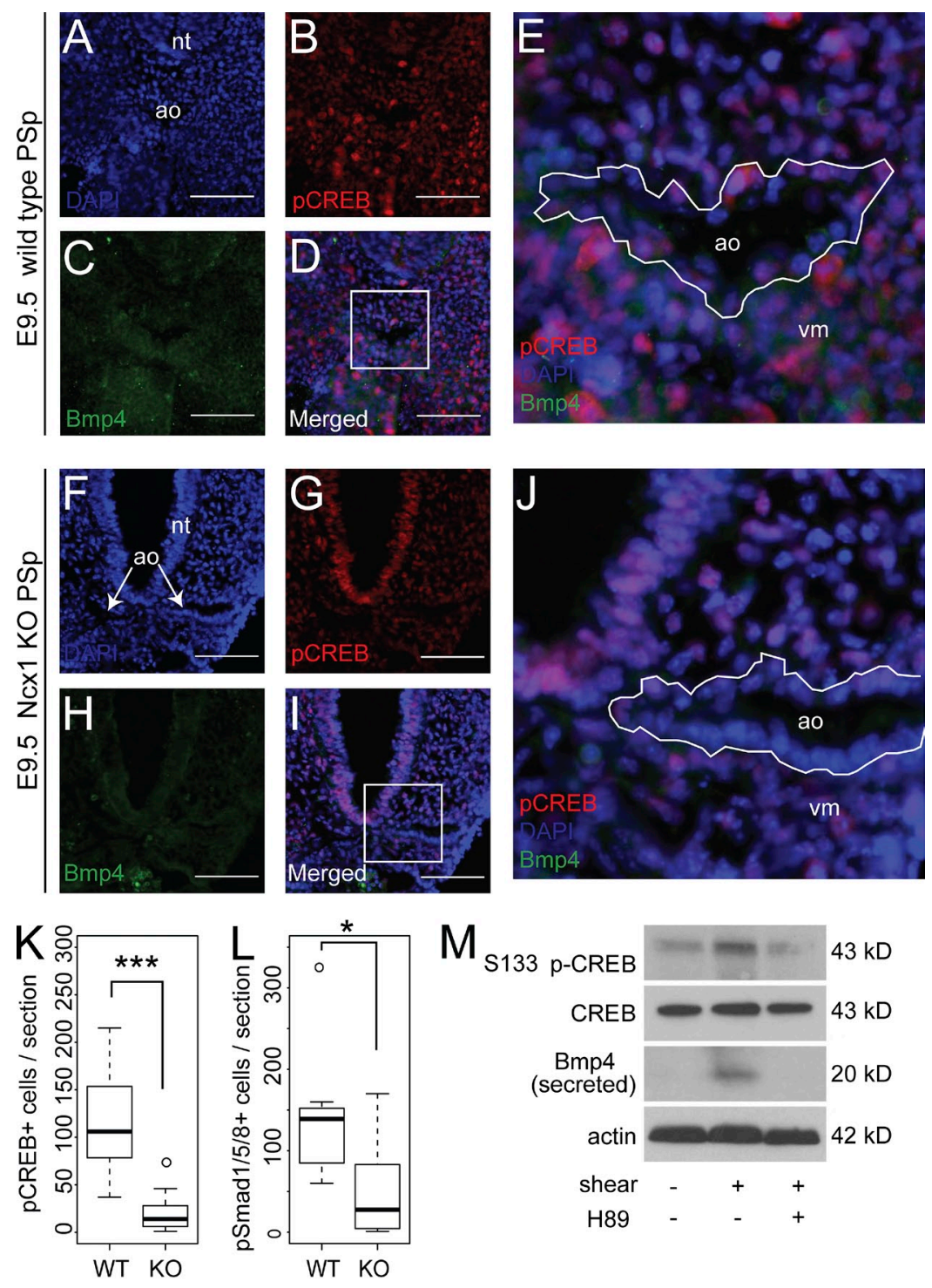

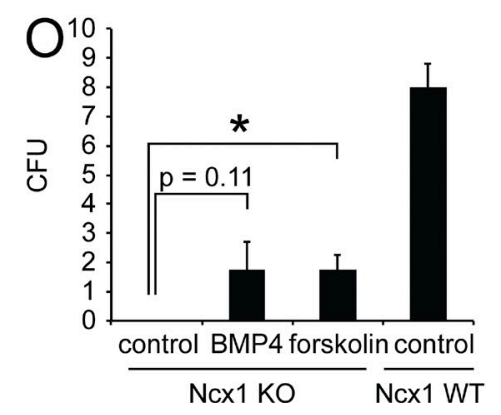

Figure 6. Shear stress-dependent regulation of CREB-BMP axis. (A-E) Frozen sections of the E9.5 wild-type PSp stained with phospho-CREB and Bmp4. (D-E) Merged image of A-C. (E) Magnified view of the boxed area in D. ao, dorsal aorta/e; nt, neural tube; vm, ventral mesenchyme. Bars, $100 \mu \mathrm{m}$. White outline contains cells facing the lumen of the dorsal aorta. (F-J) Frozen sections of the E9.5 Ncx1-null PSp with two dorsal aortae stained with phospho-CREB, Bmp4. (I-J) Merged image of F-H. (J) Magnified view of the boxed area in I. White outline contains cells facing the lumen of the dorsal aorta. (K) Quantification of phospho-CREB excluding cells in the neural tube in WT and Ncx1 KO embryos. Quantification based on three independent embryos. (L) Quantification of phospho-Smad1/5/8 excluding cells in the neural tube in WT and $\mathrm{Ncx} 1 \mathrm{KO}$ embryos. Quantification based on three independent embryos. (M) Immunoblot showing the effect of shear stress and/or PKA inhibitor H89 on phospho-CREB, Bmp4, on VE-cadherin+ cells sorted from the AGM. (N) Differential effect of laminar shear stress (LS) and oscillatory shear stress (OS) on the expression of BMP4 in endothelial cells (GSE20739; Ni et al., 2011). $n=3$.

(0) Rescue of defective hematopoiesis in E9.5 Ncx1 PSp with forskolin or BMP4 treatment. $n=4$.

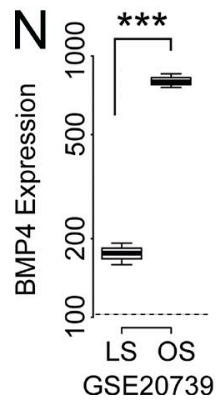

the PKA-CREB-BMP signaling axis (Fig. 6 O). Collectively, our data suggests that the PKA-CREB-BMP axis is a blood flow-dependent signaling axis responsible for hematopoietic development.

\section{DISCUSSION}

In this study, we have shown that the PKA-CREB pathway is a novel shear-responsive pathway that acts via BMP to promote AGM hematopoiesis. Chemical modulation of the PKA-CREB-BMP signaling axis implicates PKA-CREB signaling as necessary for AGM hematopoiesis, and demonstrates dependence on BMP type I receptors. Surprisingly, $\mathrm{VE}$-cadherin ${ }^{+}$cells secrete BMP ligands in response to the activation of PKA-CREB, thus promoting hematopoietic development in neighboring VE-cadherin ${ }^{+}$cells in an autocrineparacrine manner. At the genomic level, the BMP target SMAD1 
and CREB co-regulate several factors involved in hematopoietic induction, such as Gata2. In Ncx1-null embryos lacking intravascular flow, the PKA-CREB-BMP signaling axis is blunted. Our data establish a mechanism by which mechanical forces are translated into molecular signals for governing HSC emergence.

The relationship between biomechanical forces and hematopoietic development has only recently begun to be elucidated (Adamo et al., 2009; North et al., 2009; Wang et al., 2011). The striking correlation between the onset of a heartbeat at E8.5 in the mouse, and the emergence of HSCs with the ability to engraft various types of recipients - such as neonatal recipients at E9 (Yoder et al., 1997; Arora et al., 2014), and adult recipients at E10-11 (Medvinsky and Dzierzak, 1996; North et al., 2002)—suggests that biomechanical forces and hematopoietic development are intricately linked. Past studies have focused on the nitric oxide pathway as an important mediator of shear stress (Adamo et al., 2009; North et al., 2009; Wang et al., 2011). Blastula transplantation experiments in zebrafish have demonstrated a cell autonomous requirement for nitric oxide signaling during hematopoietic development (North et al., 2009), but further work is required to decipher whether nitric oxide has a direct inductive effect on hematopoietic precursors or whether this is a secondary effect caused by vasodilation. Shear-dependent programs in zebrafish and mouse may also differ because blood flow is not required for the initiation of runx $1^{+}$definitive hematopoiesis in zebrafish (Wang et al., 2011), but is required for hematopoietic colony formation from the E9 mouse PSp, an early precursor to the AGM (Adamo et al., 2009). Here, we show that the PKA-CREB-BMP signaling axis is a novel shear-dependent pathway that has a direct inductive effect on VE-cadherin ${ }^{+}$precursors. This induction of a hematopoietic program in VE-cadherin ${ }^{+}$cells involves a phenomenon called the endothelial-to-hematopoietic transition because our effects are specific to the VE-cadherin ${ }^{+}$but not the VEcadherin $^{-}$fraction, which contain mature hematopoietic cells. Indeed, most of the emerging hemogenic endothelial cells as defined by Sca1-GFP are also phospho-CREB ${ }^{+}$. Interestingly, activation of PKA results in up-regulation of Foxc2, which has been recently identified to play a role in the hemogenic endothelium (Jang et al., 2015). The endothelial-tohematopoietic transition has garnered recent interest because lineage tracing and live-imaging studies have shown that HSCs emerge from the VE-cadherin ${ }^{+}$vascular endothelium in the AGM (Chen et al., 2009; Bertrand et al., 2010; Boisset et al., 2010). Efforts to understand this phenomenon in humans have culminated in various protocols for ESC differentiation (Kennedy et al., 2012).

Numerous studies on BMP signaling and AGM hematopoietic development have hinted at its role in the endothelialto-hematopoietic transition. Bmp4 was originally identified in the murine stromal lines derived from the urogenital ridges of the AGM and have been found to increase the in vivo repopulating ability of AGM HSCs when co-cultured with stromal lines for $3 \mathrm{~d}$ (Durand et al., 2007). In their model,
Bmp4 is a ventral signal arising from the mesenchyme that promotes hematopoietic development. Zebrafish data largely fine-tunes this theory by suggesting that the BMP ligands from the ventral mesenchyme and the pronephros region polarize the dorsal aorta opposed with Hedgehog ligands from the notochord (Wilkinson et al., 2009). In our study, BMP ligands are also found ventrally, but we propose a new source of BMP ligands in the AGM that has been previously underappreciated. We suggest that BMP ligands are generated autonomously within VE-cadherin ${ }^{+}$cells upon PKA-CREB stimulation via shear stress (Figs. 4 I and 5 A). Combined with other signals from the mesenchyme, BMP ligands activate a hematopoietic transcriptional program in neighboring VEcadherin $^{+}$cells that have been exposed to shear stress, thus promoting HSC emergence. Emerging hemogenic endothelial cells have the signature of global BMP target gene upregulation. Evidence suggests that $\mathrm{CREB}$ can directly bind to the promoter of genes encoding BMP ligands in other cell types (Zhang et al., 2011). However, the question of direct binding of CREB to this promoter remains to be answered in the rare AGM cells that give rise to HSCs. Although we did not deplete the rare CD41 or CD45 positive hematopoietic fractions, the observed hematopoietic output after $8 \mathrm{~h}$ exposure to chemicals and ligands is suggestive of cell fate transitions rather than hematopoietic cell division. To confirm this, we calculated the mean doubling time of AGM hematopoietic cells using published data (Taoudi et al., 2008). Because E11.5 AGM-derived cells undergo expansion from $\sim 3,640-32,130$ cells in a 96-h period, we estimated that the doubling time is $\sim 30 \mathrm{~h}$, which is much greater than our exposure time in distinct cell types.

The ligand and mechanosensors responsible for the activation of PKA is still in question. Many different signaling modules can activate PKA, including prostaglandins (e.g., $\mathrm{PGE}_{2}$ ) through the prostanoid receptor (Goessling et al., 2009); inflammatory cytokines through interferon signaling (Liu et al., 2004), calcium flux, purinergic (Jing et al.; accompanying paper); and $\beta$-adrenergic signaling. Because of recent evidence suggesting that $\mathrm{PGE}_{2}$ is synthesized in response to shear stress (Cherian et al., 2003; Ogawa et al., 2014), and the proposed role of $\mathrm{PGE}_{2}$ in embryonic hematopoiesis (Goessling et al., 2009), $\mathrm{PGE}_{2}$ is a candidate upstream of PKA for the exploration of shear stress-mediated signaling (Diaz et al.; accompanying paper). Indeed, $\mathrm{PGE}_{2}$ can up-regulate $B M P 4$ in human $\mathrm{CD} 34^{+}$cord blood cells (Goessling et al., 2011). However, as many of these pathways can activate PKA, further studies will be required to dissect the relative contributions of individual pathways that signal through PKA-CREB.

Biomechanical forces likely have a multifactorial effect on emerging HSC precursors that cannot be replicated by the modulation of a single signaling pathway. Although the PKACREB-BMP signaling axis is necessary for HSC emergence, the modest and incomplete rescue of Ncx1 KO embryos upon exogenous administration of BMP ligands or PKA agonists suggest that other pathways, such as Wnt or Notch pathways, are also at play. 
This current study shows using sorted VE-cadherin ${ }^{+}$cells from the mouse AGM as well as Ncx1-null embryos that the PKA-CREB-BMP signaling axis is a blood flow-dependent pathway that has hematopoietic inductive effects on VEcadherin $^{+}$cells. Further studies will help explain the concentration-dependent effects of the PKA-CREB and BMP pathways and address why only rare cells are endowed with the required gene expression programs to become HSCs. Study of the signaling pathways linking biomechanical stimuli to intracellular events will help elucidate the pathways required to promote HSC formation from ESCs for cellular therapy.

\section{MATERIALS AND METHODS}

Cell culture and differentiation. mESCs were cultured on irradiated CF1s with leukemia inhibitory factor (LIF), as previously described (Kim et al., 2013). Embryoid body differentiation was performed as previously described (Kim et al., 2013). In brief, mESCs were aggregated via hanging drop method, and then collected on day 2-2.25, and then collected on day 6 of differentiation and dissociated using DNase I, Collagenase IV, and Hyaluronidase for further analysis. For shear stress applications, oscillatory shear stress of $\sim 10$ dynes $/ \mathrm{cm}^{2}$ — corresponding to an order of magnitude of previous calculations (Adamo et al., 2009) — was applied to a 10-cm tissue culture dish via $150 \mathrm{rpm}$ of orbital shaking. Maximum shear stress $\left(\tau_{\max }\right)$ was approximated via $\tau_{\max }=a\left(\rho \eta(2 \pi f)^{3}\right)^{1 / 2}$, where $a$ is the orbital radius, $\rho$ is the fluid density, $\eta$ is the fluid viscosity, and $f$ is the frequency of orbit (Ley et al., 1989). Variations in shear stress were decreased via peripheral cell attachment (dela Paz et al., 2012).

Mouse embryo culture. All animal procedures were conducted according to animal care guidelines approved by the Institutional Animal Care and Use Committee at Boston Children's Hospital. E9.5, E10.5, or 11.5 staged mouse embryos were obtained using timed pregnancies of C57BL/ 6 females unless specified. The AGM region was isolated under a dissecting microscope and dissociated to single cells using DNase I, Collagenase IV, and Hyaluronidase for $20 \mathrm{~min}$. The cells were then passed through a $40-\mu \mathrm{m}$ filter and washed with IMDM. Cells were first stained with 1:10 dilution of VEcadherin (11D4.1), then labeled with anti-rat IgG2a-PE (RG7/1.30) for sorting on FACSAria or anti-PE/anti-rat MicroBeads (Miltenyi Biotec) for magnetic sorting. For magnetic sorting, each staining step was performed for $15 \mathrm{~min}$ in $2 \% \mathrm{BSA} / \mathrm{IMDM}(\mathrm{vol} / \mathrm{vol})$ at $4^{\circ} \mathrm{C}$. All antibodies were obtained from $\mathrm{BD}$ unless indicated otherwise. Cells obtained via sorting were cultured in serum-free media containing 2\% BSA/IMDM (vol/vol) supplemented with insulin-transferrin-selenium (ITS-G; Life Technologies), $25 \mu \mathrm{g} / \mathrm{ml}$ ascorbic acid, $450 \mu \mathrm{M}$ monothioglycerol, $2 \mathrm{mM}$ penicillin/streptomycin/glutamate, and $20 \mathrm{ng} / \mathrm{ml} \mathrm{VEGF} \mathrm{(R \& D} \mathrm{Systems),} 50 \mathrm{ng} / \mathrm{ml}$ IL3 (R\&D Systems), $50 \mathrm{ng} / \mathrm{ml} \mathrm{IL-6} \mathrm{(R \& D} \mathrm{Systems),} 50 \mathrm{ng} / \mathrm{ml} \mathrm{SCF}$ (R\&D Systems), $50 \mathrm{ng} / \mathrm{ml}$ FLT3L (R\& D Systems), $50 \mathrm{ng} / \mathrm{ml}$ TPO (R\&D Systems), and $50 \mathrm{ng} / \mathrm{ml}$ IL6R (SBH Sciences). The sorted cells were reaggregated in the presence of chemicals or ligands for $8 \mathrm{~h}$ in a 96-well V-bottom plate. The cells were then dissociated with enzyme-free dissociation buffer and washed with IMDM before further analysis.

CFU assays. Cells were plated into $1.5-2 \mathrm{ml}$ of methylcellulose media containing interleukin-3 (IL-3), IL-6, erythropoietin (Epo), and SCF (M3434; StemCell Technologies) as described (Kim et al., 2013). CFUs (definitive erythroid [Ery], myeloid [M], granulocyte-macrophage [GM], granulocyteerythrocyte-monocyte-megakaryocyte multilineage [GEMM]) were scored based on morphology $10 \mathrm{~d}$ after plating.

Transplantation and peripheral blood analysis. B6.SJL-Ptprca mice were used at 6-10 wk of age. Mice were irradiated with a split dose of 9GY before transplantation. Each recipient received 1 embryo equivalent of sorted cells via tail vein injection, along with $2 \times 10^{4}$ bone marrow or $2 \times 10^{5}$ splenic helper cells per experiment group from B6.SJL-Ptprca mice unless indicated otherwise. For secondary transplantations, CD $45.2^{+}$cells were isolated from recipient bone marrow and $3 \times 10^{5}$ cells were transplanted per recipient with $2 \times 10^{5}$ splenic helper cells. Peripheral blood was collected retroorbitally at the indicated time point after transplantation. Red blood cells were removed with $1 \%$ dextran sulfate/0.5\% EDTA/PBS (wt/vol) and treated with RBC lysis buffer (Sigma-Aldrich). Leukocytes were then stained in $2 \%$ serum/PBS (vol/vol) for CD45.1-FITC (A20; BD), CD45.2-PE-Cy7 (104; BioLegend), Mac1-Alexa Fluor 700 (M1/70; BioLegend), Gr1-PE (A20; BD), CD19-APC-Cy7 (6D5; BioLegend), CD3-APC (145-2C11; eBioscience), Ter119-PE-Cy5 (TER-119; eBioscience), B220-Pacific Blue (RA3-6B2; BD), and propidium iodide (PI). Engraftment was determined to be a percentage of PI and Ter119-negative CD45.2 cells within the CD45-positive population.

Western blotting. Cells were lysed in RIPA buffer with protease and phosphatase inhibitors (Thermo Fisher Scientific). Proteins were separated via polyacrylamide gel and transferred to an activated PVDF Membrane. Membrane was blocked for $1 \mathrm{~h}$ using $5 \%$ milk or 5\% BSA in PBST or Odyssey Blocking Buffer (LI-COR) and probed with primary antibodies overnight at $4^{\circ} \mathrm{C}$. After washing with PBST, HRP-conjugated secondary antibodies were used for $1 \mathrm{~h}$ at room temperature (GE Healthcare). Protein level was detected using SuperSignal West Pico and Femto Luminol reagents (Thermo Fisher Scientific). The following antibodies were used: phospho-CREB (Cell Signaling Technology), CREB (Cell Signaling Technology), phosphoS675- $\beta$-catenin (Cell Signaling Technology), active $\beta$-catenin (Cell Signaling Technology), $\beta$-catenin (BD), Bmp4 (Millipore).

High-content immunofluorescence microscopy. Cells were cultured in 96-well optical-bottom plates (Corning). Cells were fixed with $2 \%$ paraformaldehyde for $15 \mathrm{~min}$ and permeabilized with methanol at $-20^{\circ} \mathrm{C}$ for $10 \mathrm{~min}$. Cells were blocked with Odyssey Blocking Buffer (LI-COR) for $1 \mathrm{~h}$ at room temperature. Cells were stained in this blocking buffer. Primary antibody was incubated overnight and secondary antibody was incubated at room temperature for $1 \mathrm{~h}$. Cells were imaged with ImageXpress Micro. Nine image fields were collected for each well and processed with an image segmentation routine derived from CellProfiler (Carpenter et al., 2006), with Otsu global thresholding for nuclear identification. Single-cell fluorescence intensity was calculated as mean fluorescence intensity per nucleus or per cell.

Histological analysis. For paraffin sections, E10.5 or E11.5 mouse embryos were fixed in $4 \%$ paraformaldehyde on ice for $1 \mathrm{~h}$ before embedding in paraffin and sectioning. Paraffin-embedded sections were dewaxed with xylene and rehydrated with decreasing percentages of ethanol. Antigen retrieval was performed using $10 \mathrm{mM}$ sodium citrate buffer, $\mathrm{pH}$ 6.0, using a pressure cooker at $95^{\circ} \mathrm{C}$ for $30 \mathrm{~min}$.

For frozen sections, E9.5 mouse embryos were fixed in 4\% paraformaldehyde on ice for $2-3 \mathrm{~h}$, followed by equilibration in 30\% sucrose in PBS solution overnight. The tissues were placed in 1:1 30\% sucrose/OCT (TissueTek; Electron Microscopy Sciences) solution for $1 \mathrm{~h}, 100 \%$ OCT for $1 \mathrm{~h}$, and then embedded in 100\% OCT compound. The blocks were immediately frozen on dry ice with isopropanol and stored at $-80^{\circ} \mathrm{C}$. The sections were cut at $20 \mu \mathrm{m}$ with a Leica CM3050 S cryostat.

Cells were permeabilized with Triton X-100 (0.01\%) and blocked for $1 \mathrm{~h}$ with $10 \mathrm{mM}$ glycine in host serum corresponding to the secondary antibody before staining. Immunostaining was performed with the following primary antibodies overnight: phospho-CREB (Cell Signaling Technology), CREB (Cell Signaling Technology), Bmp4 (Millipore), phospho-Smad1/5 (Cell Signaling Technology), phospho-Smad1/5/8 (Cell Signaling Technology), and GFP (Abcam). For secondary antibody staining, Alexa Fluor 488-, Alexa Fluor 568-, or Alex Fluor 647-conjugated goat anti-rabbit or goat antimouse secondary antibodies were used. DAPI-stained cells were mounted with VECTASHIELD mounting medium (Vector Labs). All images were 
obtained with Nikon Eclipse 90 i microscope with a $20 \times$ or $10 \times$ objective with CoolSNAP HQ2 (Photometrics) using NIS-Elements. Images were processed using ImageJ (National Institutes of Health).

Gene expression analysis. RNA from isolated VE-cadherin ${ }^{+}$cells was isolated with the RNeasy Micro kit (QIAGEN). RNA was hybridized to Affymetrix Mouse Genome 4302.0 Array. Microarray data were analyzed using R/Bioconductor. Raw microarray signal intensities were RMA-summarized, quantile-normalized, and filtered for duplicate genes using nsFilter to 20757 genes before analysis (Bolstad et al., 2003; Irizarry et al., 2003). Microarray data from this study has been deposited to GEO database under accession no. GSE62517. For quantitative RTPCR confirmation, RNA from isolated VE-cadherin ${ }^{+}$cells was isolated with the RNeasy Micro kit (QIAGEN). cDNAs were prepared with SuperScript III reverse transcription (Invitrogen). Quantitative RTPCR was performed with Brillian SYBR Green QPCR Mix (Strategene) on the MX3000/6P machine using primer sequences listed in Table S2. Raw microarray data is available in Table S3.

ChIP sequencing and library generation. K562 cells were grown in 10\% fetal calf serum/RPMI and serum starved at $1 \%$ serum before forskolin induction for $15 \mathrm{~h}$. K562 cells were cross-linked with $1 \%$ paraformaldehyde for $15 \mathrm{~min}$ at $20^{\circ} \mathrm{C}$. Reaction was quenched with final concentration of $0.125 \mathrm{M}$ glycine. Cells were washed with PBS, pelleted, and resuspended in SDS-ChIP buffer (20 mM Tris-HCl, pH 8.0, $150 \mathrm{mM} \mathrm{NaCl}, 2$ mM EDTA, 0.1\% SDS, and $1 \%$ Triton $\mathrm{X}-100)$ with protease inhibitor. Chromatin was sheared to $\sim 200-500$ bp with $30 \mathrm{~s} \times 5,40 \mathrm{~s} \times 12$ cycles of sonication. Sonicated chromatin was precleared with Protein-G agarose beads (Roche) and incubated with $10 \mu \mathrm{g}$ antibody overnight at $4 \mathrm{C}$. The following antibodies were used: p-CREB (scbt: sc-7978X) and p-Smad1/5/8 (scbt: sc12353X). G agarose beads were added to the ChIP reactions and incubated for $2 \mathrm{~h}$ at $4^{\circ} \mathrm{C}$. Beads were washed twice with $1 \mathrm{ml}$ of low-salt wash buffer $(50 \mathrm{mM}$ Hepes, $\mathrm{pH} 7.5$, $150 \mathrm{mM} \mathrm{NaCl}, 1 \mathrm{mM}$ EDTA, $1 \%$ Triton X-100, and $0.1 \%$ sodium deoxycholate), once with $1 \mathrm{ml}$ of high-salt wash buffer $(50 \mathrm{mM}$ Hepes, $\mathrm{pH}$ 7.5, $500 \mathrm{mM}$ $\mathrm{NaCl}, 1 \mathrm{mM}$ EDTA, $1 \%$ Triton $\mathrm{X}-100$, and $0.1 \%$ sodium deoxycholate), once with $1 \mathrm{ml}$ of $\mathrm{LiCl}$ wash buffer $(10 \mathrm{mM}$ Tris- $\mathrm{HCl}$, pH 8.0, 1 mM EDTA, $0.5 \%$ sodium deoxycholate, $0.5 \% \mathrm{NP}-40$, and $250 \mathrm{mM} \mathrm{LiCl}$ ), and twice with $1 \mathrm{ml}$ of TE buffer (10 mM Tris-HCl, $\mathrm{pH}$ 8.0, $1 \mathrm{mM}$ EDTA, $\mathrm{pH}$ 8.0). The chromatin was eluted twice in $150 \mu \mathrm{l}$ of SDS elution buffer (1\% SDS, $10 \mathrm{mM}$ EDTA, $50 \mathrm{mM}$ Tris- $\mathrm{HCl}, \mathrm{pH} 8.0)$ at $72^{\circ} \mathrm{C}$. Eluted chromatin was reverse cross-linked at $65^{\circ} \mathrm{C}$ overnight. An equal volume of TE was added the next day $(300 \mu \mathrm{l})$. ChIP DNA was treated with $1 \mu \mathrm{l}$ of RNaseA $(10 \mathrm{mg} / \mathrm{ml})$ for $1 \mathrm{~h}$ at $37^{\circ} \mathrm{C}$, and with $3 \mu \mathrm{l}$ of proteinase $\mathrm{K}(20 \mathrm{mg} / \mathrm{ml})$ for $3 \mathrm{~h}$ at $37^{\circ} \mathrm{C}$, and purified using phenol-chloroform extraction, followed by QIAquick PCR purification spin Columns (QIAGEN). Input ChIP samples were held after the preclear step and processed similarly from reverse cross-linking step to the end. Purified ChIP DNA was measured in Qubit (Invitrogen). 2-10 ng of purified ChIP DNA was used to prepare sequencing libraries (NEB next generation ChIP sequencing kit). Libraries were checked on Bio-analyzer for quality control. ChIP sequencing was performed using Illumina TM Hiseq 2000.

ChIP-seq analysis. Raw sequence read archive (SRA) files were obtained and datasets were aligned using Bowtie (version 1.0.0; Langmead et al., 2009) to build version hg19 of the human genome using the parameters $-\mathrm{k}$ 2 -m 1 -n 2 -best. SRA file IDs are compiled in Table S1. Duplicates were removed and reads were extended by 200 bp before visualization using IGVtools (Thorvaldsdóttir et al., 2013). For peak-calling, we used MACS (Model based analysis of ChIP-Seq) version 1.4.1 (Zhang et al., 2008) algorithm to identify statistically significant regions of ChIP-Seq enrichment using the threshold $\mathrm{P}$ value $1 \mathrm{e}-8$. To display binding at promoters, we calculated reads per million mapped reads per bp in $50 \mathrm{bp}$ bins $\pm 3 \mathrm{~kb}$ around the transcription start site of transcribed genes. Analysis was performed on the HMS Orchestra High Computing Cluster.

Statistical analysis. $n$ represents the number of biological replicates. Twotailed unpaired Student's $t$ tests were used unless indicated. Error bars show standard error. Statistical significance is indicated by *, $\mathrm{P}=0.05 ; * *, \mathrm{P}=$ $0.01 ; * * *, \mathrm{P}=0.001$.

Online supplemental material. Table S1, available as an Excel file, shows SRA reference IDs for ChIP-sequencing. Table S2, available as an Excel file, shows a list of primers used in this study. Table S3, available as an Excel file, shows microarray gene expression data. Online supplemental material is available at http://www.jem.org/cgi/content/full/jem.20141514/DC1.

The authors would like to thank Ryohichi Sugimura, Vanessa Lundin, Ho-Chou Tu, Yi-fen Lu, Lili Jing, and Sergei Doulatov for helpful comments.

G.Q. Daley is supported by grants from the US National Institute of Diabetes and Digestive and Kidney Diseases (R24-DK092760) and the National Heart, Lung, Blood Institute Progenitor Cell Biology Consortium (U01-HL100001), Alex's Lemonade Stand, and the Doris Duke Medical Foundation. G.O. Daley is an associate member of the Broad Institute and an investigator of the Howard Hughes Medical Institute (HHMI) and the Manton Center for Orphan Disease Research. PGK is a HHMI Medical Student Research Fellow. Informatics analysis was performed on the Harvard Medical School Orchestra High Computing Cluster. A. Nakano is supported by the American Heart Association and Eli and Edythe Broad Center of Regenerative Medicine and Stem Cell Research at UCLA.

L.I. Zon is a founder and stockholder of Fate Therapeutics, Inc. and Scholar Rock and is a scientific advisor for Stemgent. G.Q. Daley is a member of the Scientific Advisory Boards of the following companies, and receives consulting fees and/or holds equity in True North Therapeutics, Inc., Solasia, KK, Epizyme, Inc., Verastem, Inc., Ocata Therapeutics, Raze, Inc., and MPM Capital, LLP. The authors have no additional conflicts of interests to declare.

\section{Submitted: 8 August 2014}

Accepted: 12 March 2015

\section{REFERENCES}

Adamo, L., O. Naveiras, P.L. Wenzel, S. McKinney-Freeman, P.J. Mack, J. Gracia-Sancho, A. Suchy-Dicey, M. Yoshimoto, M.W. Lensch, M.C. Yoder, et al. 2009. Biomechanical forces promote embryonic haematopoiesis. Nature. 459:1131-1135. http://dx.doi.org/10.1038/nature08073

Alfranca, A., M.A. Iñiguez, M. Fresno, and J.M. Redondo. 2006. Prostanoid signal transduction and gene expression in the endothelium: role in cardiovascular diseases. Cardiovasc. Res. 70:446-456. http://dx.doi.org/10 $.1016 / j$.cardiores.2005.12.020

Arora, N., P.L. Wenzel, S.L. McKinney-Freeman, S.J. Ross, P.G. Kim, S.S. Chou, M. Yoshimoto, M.C. Yoder, and G.Q. Daley. 2014. Effect of developmental stage of HSC and recipient on transplant outcomes. Dev. Cell. 29:621-628. http://dx.doi.org/10.1016/j.devcel.2014.04.013

Barski, A., S. Cuddapah, K. Cui, T.Y. Roh, D.E. Schones, Z. Wang, G. Wei, I. Chepelev, and K. Zhao. 2007. High-resolution profiling of histone methylations in the human genome. Cell. 129:823-837. http:// dx.doi.org/10.1016/j.cell.2007.05.009

Bertrand, J.Y., N.C. Chi, B. Santoso, S. Teng, D.Y. Stainier, and D. Traver. 2010. Haematopoietic stem cells derive directly from aortic endothelium during development. Nature. 464:108-111. http://dx.doi.org/10.1038/ nature 08738

Boisset, J.C., W. van Cappellen, C. Andrieu-Soler, N. Galjart, E. Dzierzak, and C. Robin. 2010. In vivo imaging of haematopoietic cells emerging from the mouse aortic endothelium. Nature. 464:116-120. http:// dx.doi.org/10.1038/nature08764

Bolstad, B.M., R.A. Irizarry, M. Astrand, and T.P. Speed. 2003. A comparison of normalization methods for high density oligonucleotide array data based on variance and bias. Bioinformatics. 19:185-193. http://dx .doi.org/10.1093/bioinformatics/19.2.185

Carpenter, A.E., T.R. Jones, M.R. Lamprecht, C. Clarke, I.H. Kang, O. Friman, D.A. Guertin, J.H. Chang, R.A. Lindquist, J. Moffat, et al. 2006. CellProfiler: image analysis software for identifying and quantifying cell phenotypes. Genome Biol. 7:R100. http://dx.doi.org/10.1186/ gb-2006-7-10-r100

Chanda, B., A. Ditadi, N.N. Iscove, and G. Keller. 2013. Retinoic acid signaling is essential for embryonic hematopoietic stem cell development. Cell. 155:215-227. http://dx.doi.org/10.1016/j.cell.2013.08.055 
Chen, C.R., Y. Kang, P.M. Siegel, and J. Massagué. 2002. E2F4/5 and p107 as Smad cofactors linking the TGFbeta receptor to c-myc repression. Cell. 110:19-32. http://dx.doi.org/10.1016/S0092-8674(02)00801-2

Chen, M.J., T. Yokomizo, B.M. Zeigler, E. Dzierzak, and N.A. Speck. 2009 Runx1 is required for the endothelial to haematopoietic cell transition but not thereafter. Nature. 457:887-891. http://dx.doi.org/10.1038/ nature 07619

Chen, M.J., Y. Li, M.E. De Obaldia, Q. Yang, A.D. Yzaguirre, T. YamadaInagawa, C.S. Vink, A. Bhandoola, E. Dzierzak, and N.A. Speck. 2011 Erythroid/myeloid progenitors and hematopoietic stem cells originate from distinct populations of endothelial cells. Cell Stem Cell. 9:541-552. http://dx.doi.org/10.1016/j.stem.2011.10.003

Cherian, P.P., B. Cheng, S. Gu, E. Sprague, L.F. Bonewald, and J.X. Jiang. 2003. Effects of mechanical strain on the function of Gap junctions in osteocytes are mediated through the prostaglandin EP2 receptor. J. Biol. Chem. 278:43146-43156. http://dx.doi.org/10.1074/jbc.M302993200

Creyghton, M.P., A.W. Cheng, G.G. Welstead, T. Kooistra, B.W. Carey, E.J. Steine, J. Hanna, M.A. Lodato, G.M. Frampton, P.A. Sharp, et al. 2010. Histone H3K27ac separates active from poised enhancers and predicts developmental state. Proc. Natl. Acad. Sci. USA. 107:21931-21936. http://dx.doi.org/10.1073/pnas.1016071107

Davies, S.P., H. Reddy, M. Caivano, and P. Cohen. 2000. Specificity and mechanism of action of some commonly used protein kinase inhibitors. Biochem. J. 351:95-105. http://dx.doi.org/10.1042/0264-6021: 3510095

de Bruijn, M.F., X. Ma, C. Robin, K. Ottersbach, M.J. Sanchez, and E. Dzierzak. 2002. Hematopoietic stem cells localize to the endothelial cell layer in the midgestation mouse aorta. Immunity. 16:673-683. http:// dx.doi.org/10.1016/S1074-7613(02)00313-8

de Rooij, J., F.J. Zwartkruis, M.H. Verheijen, R.H. Cool, S.M. Nijman, A. Wittinghofer, and J.L. Bos. 1998. Epac is a Rap1 guanine-nucleotideexchange factor directly activated by cyclic AMP. Nature. 396:474-477. http://dx.doi.org/10.1038/24884

dela Paz, N.G., T.E. Walshe, L.L. Leach, M. Saint-Geniez, and P.A. D'Amore. 2012. Role of shear-stress-induced VEGF expression in endothelial cell survival. J. Cell Sci. 125:831-843. http://dx.doi.org/10.1242/ jcs. 084301

Durand, C., C. Robin, K. Bollerot, M.H. Baron, K. Ottersbach, and E. Dzierzak. 2007. Embryonic stromal clones reveal developmental regulators of definitive hematopoietic stem cells. Proc. Natl. Acad. Sci. USA. 104:20838-20843. http://dx.doi.org/10.1073/pnas.0706923105

Esparza, S.D., J. Chang, D.B. Shankar, B. Zhang, S.F. Nelson, and K.M. Sakamoto. 2008. CREB regulates Meis1 expression in normal and malignant hematopoietic cells. Lenkemia. 22:665-667. http://dx.doi.org/10 $.1038 /$ sj.leu.2404933

Ficara, F., M.J. Murphy, M. Lin, and M.L. Cleary. 2008. Pbx1 regulates self-renewal of long-term hematopoietic stem cells by maintaining their quiescence. Cell Stem Cell. 2:484-496. http://dx.doi.org/10.1016/j.stem .2008 .03 .004

Fitch, S.R., G.M. Kimber, N.K. Wilson, A. Parker, B. Mirshekar-Syahkal, B. Göttgens, A. Medvinsky, E. Dzierzak, and K. Ottersbach. 2012. Signaling from the sympathetic nervous system regulates hematopoietic stem cell emergence during embryogenesis. Cell Stem Cell. 11:554-566. http://dx.doi.org/10.1016/j.stem.2012.07.002

Goessling, W., T.E. North, S. Loewer, A.M. Lord, S. Lee, C.L. Stoick-Cooper, G. Weidinger, M. Puder, G.Q. Daley, R.T. Moon, and L.I. Zon. 2009. Genetic interaction of PGE2 and Wnt signaling regulates developmental specification of stem cells and regeneration. Cell.136:1136-1147.http:// dx.doi.org/10.1016/j.cell.2009.01.015

Goessling, W., R.S. Allen, X. Guan, P. Jin, N. Uchida, M. Dovey, J.M. Harris, M.E. Metzger, A.C. Bonifacino, D. Stroncek, et al. 2011. Prostaglandin E2 enhances human cord blood stem cell xenotransplants and shows long-term safety in preclinical nonhuman primate transplant models. Cell Stem Cell. 8:445-458. http://dx.doi.org/10.1016/j.stem.2011.02 .003

Gonzalez, G.A., and M.R. Montminy. 1989. Cyclic AMP stimulates somatostatin gene transcription by phosphorylation of CREB at serine 133 . Cell. 59:675-680. http://dx.doi.org/10.1016/0092-8674(89)90013-5
Hino, S., C. Tanji, K.I. Nakayama, and A. Kikuchi. 2005. Phosphorylation of beta-catenin by cyclic AMP-dependent protein kinase stabilizes betacatenin through inhibition of its ubiquitination. Mol. Cell. Biol. 25:90639072. http://dx.doi.org/10.1128/MCB.25.20.9063-9072.2005

Irizarry, R.A., B. Hobbs, F. Collin, Y.D. Beazer-Barclay, K.J. Antonellis, U. Scherf, and T.P. Speed. 2003. Exploration, normalization, and summaries of high density oligonucleotide array probe level data. Biostatistics. 4:249-264. http://dx.doi.org/10.1093/biostatistics/4.2.249

Jang, I.H., Y.F. Lu, L. Zhao, P.L. Wenzel, T. Kume, S.M. Datta, N. Arora, J. Guiu, M. Lagha, P.G. Kim, et al. 2015. Notch1 acts via Foxc2 to promote definitive hematopoiesis via effects on hemogenic endothelium. Blood. 125:1418-1426. http://dx.doi.org/10.1182/blood-2014-04-568170

Ji, R.P., C.K. Phoon, O. Aristizábal, K.E. McGrath, J. Palis, and D.H. Turnbull. 2003. Onset of cardiac function during early mouse embryogenesis coincides with entry of primitive erythroblasts into the embryo proper. Circ. Res. 92:133-135. http://dx.doi.org/10.1161/01.RES $.0000056532 .18710 . \mathrm{C} 0$

Jolma, A., T. Kivioja, J. Toivonen, L. Cheng, G. Wei, M. Enge, M. Taipale, J.M. Vaquerizas, J.Yan, M.J. Sillanpää, et al. 2010. Multiplexed massively parallel SELEX for characterization of human transcription factor binding specificities. Genome Res. 20:861-873. http://dx.doi.org/10.1101/ gr.100552.109

Kennedy, M., G. Awong, C.M. Sturgeon, A. Ditadi, R. LaMotte-Mohs, J.C. Zúñiga-Pflücker, and G. Keller. 2012. T lymphocyte potential marks the emergence of definitive hematopoietic progenitors in human pluripotent stem cell differentiation cultures. Cell Reports. 2:1722-1735. http://dx.doi.org/10.1016/j.celrep.2012.11.003

Kim, P.G., C.E. Albacker, Y.F. Lu, I.H. Jang, Y. Lim, G.C. Heffner, N. Arora, T.V. Bowman, M.I. Lin, M.W. Lensch, et al. 2013. Signaling axis involving Hedgehog, Notch, and $\mathrm{Scl}$ promotes the embryonic endothelial-to-hematopoietic transition. Proc. Natl. Acad. Sci. USA 110:E141-E150. http://dx.doi.org/10.1073/pnas.1214361110

Koch, C.M., R.M. Andrews, P. Flicek, S.C. Dillon, U. Karaöz, G.K. Clelland, S. Wilcox, D.M. Beare, J.C. Fowler, P. Couttet, et al. 2007. The landscape of histone modifications across $1 \%$ of the human genome in five human cell lines. Genome Res. 17:691-707. http://dx.doi .org/10.1101/gr.5704207

Koushik, S.V., J. Wang, R. Rogers, D. Moskophidis, N.A. Lambert, T.L. Creazzo, and S.J. Conway. 2001. Targeted inactivation of the sodiumcalcium exchanger $(\mathrm{Ncx} 1)$ results in the lack of a heartbeat and abnormal myofibrillar organization. FASEB J. 15:1209-1211.

Kretzschmar, M., F. Liu, A. Hata, J. Doody, and J. Massagué. 1997. The TGF-beta family mediator Smad1 is phosphorylated directly and activated functionally by the BMP receptor kinase. Genes Dev. 11:984-995. http://dx.doi.org/10.1101/gad.11.8.984

Langmead, B., C. Trapnell, M. Pop, and S.L. Salzberg. 2009. Ultrafast and memory-efficient alignment of short DNA sequences to the human genome. Genome Biol. 10:R25. http://dx.doi.org/10.1186/gb-2009-10-3-r25

Ley, K., E. Lundgren, E. Berger, and K.E. Arfors. 1989. Shear-dependent inhibition of granulocyte adhesion to cultured endothelium by dextran sulfate. Blood. 73:1324-1330.

Ling, K.W., K. Ottersbach, J.P. van Hamburg, A. Oziemlak, F.Y. Tsai, S.H. Orkin, R. Ploemacher, R.W. Hendriks, and E. Dzierzak. 2004. GATA-2 plays two functionally distinct roles during the ontogeny of hematopoietic stem cells. J. Exp. Med. 200:871-882. http://dx.doi.org/ 10.1084/jem.20031556

Liu, L., Y. Wang, Y. Fan, C.L. Li, and Z.L. Chang. 2004. IFN-gamma activates $\mathrm{CAMP} / \mathrm{PKA} / \mathrm{CREB}$ signaling pathway in murine peritoneal macrophages. J. Interferon Cytokine Res. 24:334-342.

Lux, C.T., M. Yoshimoto, K. McGrath, S.J. Conway, J. Palis, and M.C. Yoder. 2008. All primitive and definitive hematopoietic progenitor cells emerging before E10 in the mouse embryo are products of the yolk sac. Blood. 111:3435-3438. http://dx.doi.org/10.1182/blood-2007-08-107086

Lyden, D., A.Z. Young, D. Zagzag, W. Yan, W. Gerald, R. O'Reilly, B.L. Bader, R.O. Hynes, Y. Zhuang, K. Manova, and R. Benezra. 1999. Id1 and Id 3 are required for neurogenesis, angiogenesis and vascularization of tumour xenografts. Nature. 401:670-677. http://dx.doi.org/10 $.1038 / 44334$ 
Marshall, C.J., J.C. Sinclair, A.J. Thrasher, and C. Kinnon. 2007. Bone morphogenetic protein 4 modulates c-Kit expression and differentiation potential in murine embryonic aorta-gonad-mesonephros haematopoiesis in vitro. Br. J. Haematol. 139:321-330. http://dx.doi.org/10.1111/ j.1365-2141.2007.06795.x

Martens, J.H., A. Mandoli, F. Simmer, B.J. Wierenga, S. Saeed, A.A. Singh, L. Altucci, E. Vellenga, and H.G. Stunnenberg. 2012. ERG and FLI1 binding sites demarcate targets for aberrant epigenetic regulation by AML1-ETO in acute myeloid leukemia. Blood. 120:4038-4048. http:// dx.doi.org/10.1182/blood-2012-05-429050

McKinney-Freeman, S., P. Cahan, H. Li, S.A. Lacadie, H.T. Huang, M. Curran, S. Loewer, O. Naveiras, K.L. Kathrein, M. Konantz, et al. 2012. The transcriptional landscape of hematopoietic stem cell ontogeny. Cell Stem Cell. 11:701-714. http://dx.doi.org/10.1016/j.stem.2012.07.018

Medvinsky, A., and E. Dzierzak. 1996. Definitive hematopoiesis is autonomously initiated by the AGM region. Cell. 86:897-906. http://dx.doi .org/10.1016/S0092-8674(00)80165-8

Mi, H., N. Guo, A. Kejariwal, and P.D. Thomas. 2007. PANTHER version 6: protein sequence and function evolution data with expanded representation of biological pathways. Nucleic Acids Res. 35(Database):D247D252. http://dx.doi.org/10.1093/nar/gk1869

Moore, M.A., and D. Metcalf. 1970. Ontogeny of the haemopoietic system: yolk sac origin of in vivo and in vitro colony forming cells in the developing mouse embryo. Br. J. Haematol. 18:279-296. http://dx.doi. org/10.1111/j.1365-2141.1970.tb01443.x

Nagase, T., M. Nagase, K. Yoshimura, M. Machida, and M. Yamagishi. 2006. Defects in aortic fusion and craniofacial vasculature in the holoprosencephalic mouse embryo under inhibition of sonic hedgehog signaling. J. Craniofac. Surg. 17:736-744. http://dx.doi.org/10.1097/00001665200607000-00026

Ni, C.W., H. Qiu, and H. Jo. 2011. MicroRNA-663 upregulated by oscillatory shear stress plays a role in inflammatory response of endothelial cells. Am. J. Physiol. Heart Circ. Physiol. 300:H1762-H1769. http://dx.doi .org/10.1152/ajpheart.00829.2010

North, T.E., M.F. de Bruijn, T. Stacy, L. Talebian, E. Lind, C. Robin, M. Binder, E. Dzierzak, and N.A. Speck. 2002. Runx1 expression marks long-term repopulating hematopoietic stem cells in the midgestation mouse embryo. Immunity. 16:661-672. http://dx.doi.org/10.1016/ S1074-7613(02)00296-0

North, T.E., W. Goessling, M. Peeters, P. Li, C. Ceol, A.M. Lord, G.J. Weber, J. Harris, C.C. Cutting, P. Huang, et al. 2009. Hematopoietic stem cell development is dependent on blood flow. Cell. 137:736-748. http://dx.doi.org/10.1016/j.cell.2009.04.023

Ogawa, H., E. Kozhemyakina, H.H. Hung, A.J. Grodzinsky, and A.B. Lassar. 2014. Mechanical motion promotes expression of Prg4 in articular cartilage via multiple CREB-dependent, fluid flow shear stressinduced signaling pathways. Genes Dev. 28:127-139. http://dx.doi.org/ 10.1101/gad.231969.113

Pencovich, N., R. Jaschek, A. Tanay, and Y. Groner. 2011. Dynamic combinatorial interactions of RUNX1 and cooperating partners regulates megakaryocytic differentiation in cell line models. Blood. 117:e1-e14. http://dx.doi.org/10.1182/blood-2010-07-295113

Pereira, C.F., B. Chang, J. Qiu, X. Niu, D. Papatsenko, C.E. Hendry, N.R. Clark, A. Nomura-Kitabayashi, J.C. Kovacic, A. Ma'ayan, et al. 2013. Induction of a hemogenic program in mouse fibroblasts. Cell Stem Cell. 13:205-218. http://dx.doi.org/10.1016/j.stem.2013.05.024

Raney, B.J., M.S. Cline, K.R. Rosenbloom, T.R. Dreszer, K. Learned, G.P. Barber, L.R. Meyer, C.A. Sloan, V.S. Malladi, K.M. Roskin, et al. 2011. ENCODE whole-genome data in the UCSC genome browser (2011 update). Nucleic Acids Res. 39(Database):D871-D875. http:// dx.doi.org/10.1093/nar/gkq1017

Ruiz-Herguido, C., J. Guiu, T. D’Altri, J. Inglés-Esteve, E. Dzierzak, L. Espinosa, and A. Bigas. 2012. Hematopoietic stem cell development requires transient Wnt/ $\beta$-catenin activity. J. Exp. Med. 209:1457-1468. http://dx.doi.org/10.1084/jem.20120225
Swiers, G., C. Baumann, J. O’Rourke, E. Giannoulatou, S. Taylor, A. Joshi, V. Moignard, C. Pina, T. Bee, K.D. Kokkaliaris, et al. 2013. Early dynamic fate changes in haemogenic endothelium characterized at the single-cell level. Nat. Commun. 4:2924. http://dx.doi.org/ 10.1038/ncomms3924

Taoudi, S., C. Gonneau, K. Moore, J.M. Sheridan, C.C. Blackburn, E. Taylor, and A. Medvinsky. 2008. Extensive hematopoietic stem cell generation in the AGM region via maturation of VE-cadherin+CD45+ pre-definitive HSCs. Cell Stem Cell. 3:99-108. http://dx.doi.org/10 $.1016 /$ j.stem.2008.06.004

Thorvaldsdóttir, H., J.T. Robinson, and J.P. Mesirov. 2013. Integrative Genomics Viewer (IGV): high-performance genomics data visualization and exploration. Brief. Bioinform. 14:178-192. http://dx.doi.org/10 1093/bib/bbs017

Trompouki, E., T.V. Bowman, L.N. Lawton, Z.P. Fan, D.C. Wu, A DiBiase, C.S. Martin, J.N. Cech, A.K. Sessa, J.L. Leblanc, et al. 2011 Lineage regulators direct BMP and Wnt pathways to cell-specific programs during differentiation and regeneration. Cell. 147:577-589. http:// dx.doi.org/10.1016/j.cell.2011.09.044

Vermot, J., A.S. Forouhar, M. Liebling, D. Wu, D. Plummer, M. Gharib, and S.E. Fraser. 2009. Reversing blood flows act through klf2a to ensure normal valvulogenesis in the developing heart. PLoS Biol. 7:e1000246. http://dx.doi.org/10.1371/journal.pbio.1000246

Wang, L., P. Zhang, Y. Wei, Y. Gao, R. Patient, and F. Liu. 2011. A blood flow-dependent klf2a-NO signaling cascade is required for stabilization of hematopoietic stem cell programming in zebrafish embryos. Blood. 118:4102-4110. http://dx.doi.org/10.1182/blood-2011-05-353235

Wilkinson, R.N., C. Pouget, M. Gering, A.J. Russell, S.G. Davies, D. Kimelman, and R. Patient. 2009. Hedgehog and Bmp polarize hematopoietic stem cell emergence in the zebrafish dorsal aorta. Dev. Cell. 16:909-916. http://dx.doi.org/10.1016/j.devcel.2009.04.014

Wilson, B.E., E. Mochon, and L.M. Boxer. 1996. Induction of bcl-2 expression by phosphorylated CREB proteins during B-cell activation and rescue from apoptosis. Mol. Cell. Biol. 16:5546-5556.

Yamamizu, K., T. Matsunaga, S. Katayama, H. Kataoka, N. Takayama, K. Eto, S. Nishikawa, and J.K. Yamashita. 2012. PKA/CREB signaling triggers initiation of endothelial and hematopoietic cell differentiation via Etv2 induction. Stem Cells. 30:687-696. http://dx.doi.org/10.1002/ stem.1041

Yoder, M.C., K. Hiatt, P. Dutt, P. Mukherjee, D.M. Bodine, and D. Orlic. 1997. Characterization of definitive lymphohematopoietic stem cells in the day 9 murine yolk sac. Immunity. 7:335-344. http://dx.doi.org/10 .1016/S1074-7613(00)80355-6

Yu, P.B., D.Y. Deng, C.S. Lai, C.C. Hong, G.D. Cuny, M.L. Bouxsein, D.W. Hong, P.M. McManus, T. Katagiri, C. Sachidanandan, et al. 2008a. BMP type I receptor inhibition reduces heterotopic [corrected] ossification. Nat. Med. 14:1363-1369. http://dx.doi.org/10.1038/nm.1888

Yu, P.B., C.C. Hong, C. Sachidanandan, J.L. Babitt, D.Y. Deng, S.A. Hoyng, H.Y. Lin, K.D. Bloch, and R.T. Peterson. 2008b. Dorsomorphin inhibits BMP signals required for embryogenesis and iron metabolism. Nat. Chem. Biol. 4:33-41. http://dx.doi.org/10.1038/nchembio.2007.54

Zhang, X., D.T. Odom, S.H. Koo, M.D. Conkright, G. Canettieri, J. Best, H. Chen, R. Jenner, E. Herbolsheimer, E. Jacobsen, et al. 2005. Genomewide analysis of cAMP-response element binding protein occupancy, phosphorylation, and target gene activation in human tissues. Proc. Natl. Acad. Sci. USA. 102:4459-4464. http://dx.doi.org/10.1073/pnas.0501076102

Zhang, Y., T. Liu, C.A. Meyer, J. Eeckhoute, D.S. Johnson, B.E. Bernstein, C. Nusbaum, R.M. Myers, M. Brown, W. Li, and X.S. Liu. 2008 Model-based analysis of ChIP-Seq (MACS). Genome Biol. 9:R137. http:// dx.doi.org/10.1186/gb-2008-9-9-r137

Zhang, R., J.R. Edwards, S.Y. Ko, S. Dong, H. Liu, B.O. Oyajobi, C. Papasian, H.W. Deng, and M. Zhao. 2011. Transcriptional regulation of BMP2 expression by the PTH-CREB signaling pathway in osteoblasts. PLoS ONE. 6:e20780. http://dx.doi.org/10.1371/journal .pone. 0020780 